\title{
El cultivo tradicional del almendro en el Mediterráneo: Baleares en el contexto español (ca. 1770-2017)
}

\author{
ANTÒnia Morey y JaUme FornéS
}

\begin{abstract}
PALABRAS CLAVE: producción de almendra, cultivo del almendro, Baleares-siglos XVIII-XXI, España-siglos XVIII-XXI.
\end{abstract}

\section{CÓDIGOS JEL: N53, N54, Q17, R14.}

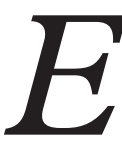

l proceso de diversificación arbórea iniciado en España en la etapa final del Antiguo Régimen propicia el surgimiento de nuevas áreas productoras $y$ nuevos cultivos. Algunas regiones mediterráneas, en especial Baleares, destacaron por la temprana dedicación al cultivo en secano del almendro. Su trayectoria se ha relacionado, sobre todo, con la evolución del valor comercial de la almendra obviando, a menudo, otros aprovechamientos del árbol: abono, alimento para el ganado, leña, etc. Sin embargo, en los sistemas agrarios tradicionales, como sucedió también con otros cultivos, su carácter multifuncional resultó de gran importancia para el reinicio de los ciclos productivos de muchas explotaciones agrarias; en especial para las unidades campesinas. En Baleares, los moderados rendimientos del almendral y la competencia ejercida, sobre todo a partir de la segunda mitad del siglo XX, por otras áreas de producción nacional e internacional no desincentivaron su cultivo. El desarrollo se vio favorecido, al igual que en otras regiones, por los sucesivos planes de mejora financiados desde la década de 1960 por distintas instituciones gubernamentales: primero por el Gobierno de España y más recientemente por la Comunidad Europea. Sin embargo, en los últimos años una bacteria con un alto poder destructivo (Xylella fastidiosa) amenaza la pervivencia de los almendrales. 


\section{Traditional almond cultivation in the Mediterranean: Balearic Islands in the Spanish context} (ca. 1770-2017)

\section{KEYWORDS: almond production, almond cultivation, Balearics- $18^{\text {th }}-21^{\text {st }}$ centuries, Spain-18 ${ }^{\text {th }}-21^{\text {st }}$.}

\section{JEL CODES: N53, N54, Q17, R14.}

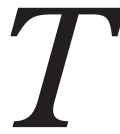

The process of arboreal diversification that was initiated in Spain in the final stage of the Old Regime propitiated the emergence of new areas of production and crops. Some Mediterranean regions, and in particular the Balearic Islands, stood out for the early dry farming cultivation of almond trees. Its development has been related above all to the evolution of the commercial value of almonds, often ignoring other uses of the tree: fertilizer, fodder for livestock, firewood, etc. But in traditional agrarian systems, as with other crops, their multifunctionality was extremely important for the reinitiation of productive cycles on many farms; especially for peasant units. In the Balearic Islands, the moderate yields of almond plantations and the competition exercised by other national and international areas of production, in particular from the second half of the $20^{\text {th }}$ century on, did not discourage cultivation of them. As in other regions, development was favoured by successive improvement plans financed from the 1960s on by different government institutions: first by the government of Spain, and more recently by the European Community. However, over recent years, a highly destructive bacteria (Xylella fastidiosa) has not only discouraged cultivation, but threatens the survival of one of the most characteristic trees of the agricultural landscape of the islands.

Recepción: 2019-10-01 - Revisión: 2020-07-03 - Aceptación: 2020-07-06

Antònia Morey [orcid.org/0000-0002-5697-4803] es profesora titular del Departamento de Economía Aplicada en la Universitat de les Illes Balears, miembro del Grup d'Investigació Agrària de les Illes Balears (GIAIB) y del Grup d'Estudis d'Història Econòmica. Dirección para correspondencia: Departamento de Economía Aplicada, Edificio G. M. de fovellanos, campus de la Universitat de les Illes Balears, ctra. de Valldemossa, km 7,5,07122 Palma (España).C.e.: antonia.morey@uib.es

Jaume Fornés [orcid.org/0000-0002-5632-1458] es licenciado en Geografía por la Universitat de les Illes Balears y doctorando del programa Historia, Historia del Arte y Geografía de la misma universidad, además de miembro del Grup d'Investigació Agrària de les Illes Balears (GIAIB). Dirección para correspondencia: Departamento de Economía Aplicada, Edificio G. M. de Fovellanos, campus de la Universitat de les Illes Balears, ctra.deValldemossa, km 7,5,07122 Palma (España).C.e.:jaumefornes@gmail.com 


\section{TEMA DE ESTUDIO}

El cultivo del almendro en las regiones mediterráneas presenta una dilatada trayectoria que le ha permitido resistir, en parte, los embates de las plantaciones americanas cultivadas de forma intensiva ${ }^{1}$. Este trabajo pretende mostrar su permanencia en una de las regiones del Mediterráneo español (Baleares) donde se extendió de forma temprana y en la que ha sido considerado uno de los árboles más característicos del paisaje agrario de las islas de Mallorca e Ibiza. Desde los inicios de su expansión hasta fechas recientes se ha cultivado mayoritariamente en secano, a partir de variedades autóctonas y asociado a otros cultivos que han contribuido a la reproducción del ciclo productivo de las explotaciones agrarias. De ahí el interés por relacionar la resistencia del almendro con su carácter multifuncional y no solo con el valor comercial del fruto ${ }^{2}$. Pretendemos enfatizar, por un lado, el papel pionero de las islas en la expansión del cultivo y establecer, por otro, las principales fases de su evolución histórica teniendo en cuenta los distintos aprovechamientos del árbol.

Se aborda la evolución del almendro desde el último tercio del siglo XviII hasta el año 2016-2017 en que, por las deficiencias estructurales que se venían arrastrando y por la irrupción de una bacteria (Xylella fastidiosa) con un alto poder destructivo, el cultivo se encuentra en regresión. Con estas premisas, y tras la presentación del tema de estudio, la investigación se ordena en los apartados siguientes: fuentes documentales; aprovechamientos del cultivo; el almendro en las Baleares antes de la expansión masiva (1780-1900); principales ventajas de la especialización temprana de la región (1900-1960/1970); limitaciones comerciales del cultivo (1960/1970-1990); pervivencia del almendro en las pequeñas explotaciones (1990-2017); y conclusiones.

1. El liderazgo mundial correspondió a Italia hasta que en la década de 1960 los Estados Unidos se convirtieron en líderes indiscutibles. España fue ganando pulsaciones, pero no pudo competir con los rendimientos de las plantaciones californianas cultivadas en regadío, a partir de variedades seleccionadas, con una alta densidad de árboles por hectárea y un elevado índice de mecanización. Entre 1950-1977 la producción mediterránea crece a un ritmo del 28\%, mientras que la americana lo hace en torno a un 600\% (QUINTANA, 1981: 41-42; MURUA, 1993: 7-8). En la actualidad, la producción de almendra se concentra en un reducido número de países, y España ocupa un modesto tercer puesto: Estados Unidos (alrededor del 86\%), Australia (6\%), España (4,5\%), Turquía (1,22\%) e Italia (0,84\%) son los principales (Velasco \& AzNAR, 2016: 78; Pablo, García Azcárate \& GIACINTI, 2016; FAO, 2017).

2. Barceló (1964); Bisson (1977); Cela (1979); Florit (1983); Quintana (1979, 1981); Jover y MANera (2009); MANERA (2001: 113-194); MOREY y Fornés (2019); MORRO (2017); RosSElló (1964). 


\section{MAPA 1}

\section{Localización de las islas Baleares en el Mediterráneo occidental} y división de Mallorca y las Pitiusas en partidos judiciales

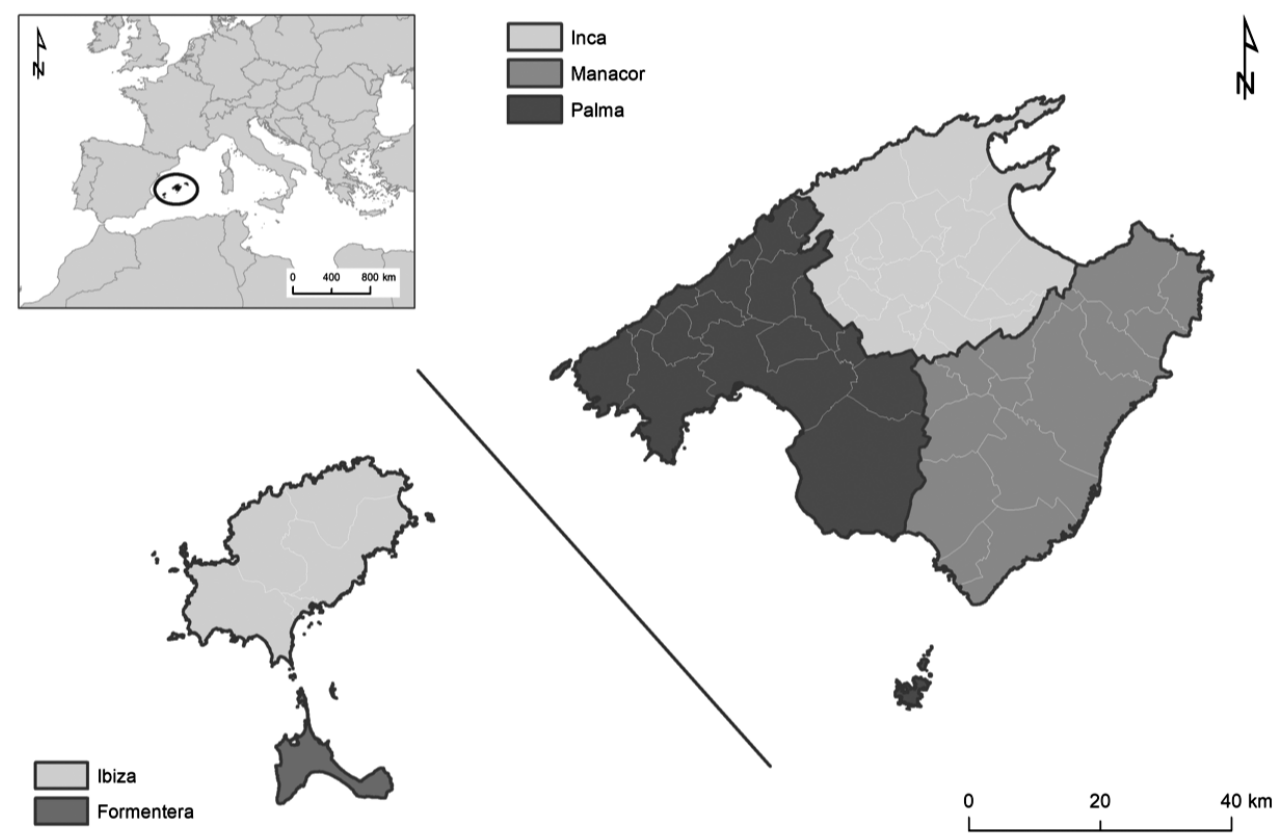

Fuente: elaboración propia a partir de la información geográfica digital producida por el Instituto Geográfico Nacional (IGN) (2020).

\section{FUENTES}

El interés por situar el caso balear en el contexto español nos ha llevado a sistematizar fuentes específicas sobre el área objeto de estudio y a explorar estadísticas históricas sobre otras provincias. Los datos de las islas proceden, fundamentalmente, de las memorias elaboradas por el Servicio Agronómico Provincial desde mediados del siglo XIX hasta la década 1950-1960 y de las publicaciones compiladas por la Cámara Oficial de Comercio de Palma de Mallorca ${ }^{3}$. Ambas fuentes contienen datos cuantitativos seriados e información cualitativa relacionada con los distintos aprovechamientos del árbol, las formas de manejo del cultivo, las principales variedades cultivadas y la comercialización del fruto. La información sobre el resto de las provincias procede de la serie de estadísticas

3. Concretamente, en el Boletín de la Cámara de Comercio, Industria y Navegación de Palma (BCOCIN, 1899-1945) y en la Memoria Comercial editada por la misma institución (MCOCIN, 1919-1945). 
históricas del Servicio Agronómico Nacional y, en particular, de los anuarios de estadística agraria $(A E A)^{4}$ del Ministerio de Agricultura, Pesca y Alimentación (MAPA). Para seguir la evolución de algunas magnitudes, se han utilizado también las encuestas del MAPA sobre superficies y rendimientos de los frutos secos (ESYRCE). Asimismo, gracias a las facilidades de la Consejería de Medio Ambiente, Agricultura y Pesca del Govern de les Illes Balears, se han podido estimar las declaraciones de superfície cultivada en el marco de las solicitudes de ayuda de la Política Agraria Comunitaria (PAC) para las campañas de 2004 y 2018.

Además de la documentación de carácter oficial, se ha sistematizado una muestra de contratos de arrendamiento estipulados durante los siglos XVIII-XIX sobre un centenar de grandes explotaciones que destacaron por su especialización almendrícola ${ }^{5}$. El análisis de dichos contratos revela numerosos aspectos relacionados con los usos y costumbres propios del cultivo. Evidencian, asimismo, el interés temprano de muchos grandes propietarios por la diversificación arbórea; una cuestión que tradicionalmente se había relacionado, de forma prácticamente exclusiva, con las pequeñas explotaciones campesinas. Asimismo, la sistematización de un conjunto de libros de cuentas conservados en los archivos particulares de algunos propietarios y arrendatarios de grandes explotaciones permite estimar la evolución de los costes y beneficios del cultivo en distintas épocas y constatar que, ni siquiera para las explotaciones de mayor tamaño, la importancia del almendro fue exclusivamente comercial ${ }^{6}$. Desde otra perspectiva, la realización de un conjunto de entrevistas a diversos actores relacionados con el sector (pequeños y grandes propietarios, antiguos colonos, representantes de cooperativas agrarias, comerciantes, etc.) ha sido crucial para entender la situación actual del cultivo. Por último, la información obtenida a partir de numerosas visitas de campo ha permitido conocer, entre otros aspectos, las actuales prácticas de cultivo y las repercusiones de los sucesivos programas de modernización del sector sobre la biodiversidad cultivada ${ }^{7}$.

4. Para la información sobre los cultivos leñosos (no recogida en los $A E A$ de forma sistemática hasta después de 1928), véase la compilación del GRUPO DE Estudios DE Historia RURAL (1991). Interesa no perder de vista, sin embargo, la precaución con la que deben interpretarse las estadísticas oficiales en general y los $A E A$ en particular (CARRERAS \& TAFUNELL, 2005: vol. 3, 263-273). Véase nota 36.

5. Los contratos sistematizados, alrededor de quinientos, proceden de la sección de protocolos notariales del Archivo del Reino de Mallorca (ARM). Se han podido localizar gracias a las referencias de Moll y Suau (1979), Albertí y Morey (1986) y Morey (2013, 2019).

6. Se han explorado archivos familiares de arrendatarios: Calafat (responsables durante varias generaciones de la gestión de distintas fincas del término municipal de Santa Maria) y Rosselló de Son Fortesa. Asimismo, documentación contable perteneciente a grandes propietarios de fincas almendrícolas: Sureda-Vivot, Verí, Cotoner y Servera de ca s'Hereu.

7. Las entrevistas, como las visitas de campo, se han desarrollado en el marco de una acción especial (AAEE8/2014) auspiciada por el Govern de les Illes Balears y el Fondo de Desarrollo Regio- 


\section{LOS APROVECHAMIENTOS DEL CULTIVO}

Los múltiples productos que históricamente se han obtenido del árbol, así como el marcado carácter complementario del cultivo en España, son aspectos que interesa tomar en consideración. Una realidad, que al igual que sucedió en otras áreas y también con otros cultivos $^{8}$, está en la base de su larga trayectoria en el campo balear. En el Cuadro 1 se consignan los usos principales del almendro y se pone de manifiesto que la funcionalidad del cultivo no se reducía, únicamente, a la comercialización del fruto. Contribuía al sustento de las unidades campesinas y facilitaba la organización de las explotaciones de mayor tamaño (denominadas en Mallorca possessions ${ }^{9}$ ) en dos sectores: uno comercial, orientado a la consecución de ingresos monetarios, y otro natural, que evitaba, o por lo menos minimizaba ${ }^{10}$, los gastos derivados de la compra de cereales, leguminosas, leña, pienso para el ganado, abono, etc. Este carácter multifuncional se enfatiza en las sucesivas memorias agrarias publicadas desde finales del siglo XVIII hasta mediados del siglo Xx; aunque en todas se subraya que el valor monetario del cultivo procede, fundamentalmente, de la comercialización del fruto, mientras que el rendimiento económico del resto de los aprovechamientos (a menudo denominados desperdicios) era insignificante ${ }^{11}$.

nal de la Unión Europea (FEDER). En total se han realizado más de doscientas entrevistas que, por cuestiones de espacio, resulta imposible recoger aquí y se citan en los trabajos de ForNÉs (2011).

8. Infante-Amate (2012a, 2012b, 2014); GonZÁlez de Molina, Infante-Amate y GuZmán CASAdO (2014). Sobre los cultivos leñosos en general, véanse IRIARTE-GoÑI y AYUDA (2006), IRIARTE-GoÑ (2013), INFANTE-AmATE e IRIARTE-GoÑI (2017), INFANTE-AmATE et al. (2014) y Soto (2015).

9. En Mallorca, con una superficie de $3.640 \mathrm{~km}^{2}$ equivalentes a $364.000 \mathrm{ha}$, el calificativo de gran propiedad se aplica a explotaciones generalmente más reducidas que en otras regiones. Durante el período estudiado la extensión más frecuente oscilaba entre 50 y 100 ha (JOVER \& MOREY, 2003).

10. Tello (1983); Grau (1981); Grau y Tello (1985).

11. El valor comercial de las hojas, la leña, las cáscaras verdes y otros productos obtenidos de una hectárea de almendral no superaba el 2\% del total (HABSBURG-LORENA, 1959; BALLESTER, 1910, 1922; Mestre, 1942). Sin embargo, no disponemos de los porcentajes de los distintos aprovechamientos medidos en términos de biomasa, tal y como han sido realizados para otros cultivos (INfante-Amate, 2012a, 2012b, 2014; GonZÁleZ de Molina, Infante-Amate \& GuZmán Casado, 2014). 


\section{CUADRO 1}

Destino y uso final de los productos del almendro, ca. 1800-1960/1970

\begin{tabular}{|c|c|c|}
\hline Productos & Estado & Destino y uso final del producto \\
\hline & En verde & Comercializada en su estado natural \\
\hline & & o en conserva para alimentación \\
\hline & En seco & Con la envoltura leñosa para comercio \\
\hline & & Descascarada (en pepita) para comercio \\
\hline & & Empresas de transformación: \\
\hline & & -Repostería en general y turrón en particular \\
\hline \multirow[t]{7}{*}{ Almendra } & & -Leche de almendra (uso medicinal) \\
\hline & & -Sirope para usos culinarios \\
\hline & & -Aceite de almendra (jabón y cosméticos) \\
\hline & Vanas $^{12}$ & En seco para aceite \\
\hline & & En pasta/procesadas para alimento ganado vacuno \\
\hline & En verde & Forraje para ganado lanar y cabrío \\
\hline & & Abono potásico \\
\hline
\end{tabular}

Corteza exterior

Reducida a cenizas Abono potásico

Lejías y jabón blando

\begin{tabular}{|c|c|c|}
\hline & $\begin{array}{l}\text { Molida y mezclada con } \\
\text { higos chumbos }\end{array}$ & Alimento para ganado de cerda \\
\hline \multirow{2}{*}{ Corteza interior (leñosa) } & Troceada & Combustible para motores de gas pobre \\
\hline & & Calefacción para hogares y pequeñas industrias \\
\hline \multirow[t]{2}{*}{ Hojas } & En verde & Ramoneo para ganado lanar y cabrío \\
\hline & Gruesa (árboles) & Combustible para: hogares \\
\hline \multirow[t]{2}{*}{ Leña y madera } & Menuda (podas) & Hormigueros $^{13}$ (fertilizante) \\
\hline & Madera & Muebles y otros enseres \\
\hline Goma & Procesada & Colas y pegamentos \\
\hline \multirow[t]{2}{*}{ Flor } & Natural & Estimulación inicio actividad abejas antes de la primavera \\
\hline & Procesada & Perfumes \\
\hline
\end{tabular}

Fuente: elaboración propia a partir de Ballester (1912, 1922), Estelrich (1907), Grasset de Saint-Sauveur (1952: 63), Habsburg-Lorena (1959), Riera y Lamic (1970) y Salom (1923).

12. Se trata de almendras con la semilla mal desarrollada y seca por lo que son de calidad inferior y no se destinan, en muchos casos, al consumo humano (MESTRE, 1942).

13. Los hormigueros se elaboraban a partir de montones de hierba o material leñoso cubiertos con tierra a los que se prendía fuego para posteriormente esparcirlos como fertilizante (GARRABOU \& GonZÁleZ DE Molina, 2010; OlARIETA et al., 2011; VADELl et al., 2010). 
Las ovejas pastaban, ya fuera en otoño o después de la poda, en las tierras de almendral y, además de la cubierta vegetal, aprovechaban las hojas y las ramas cortadas que había en el suelo; la corteza verde era también utilizada como forraje para el ganado ovino y caprino, y la corteza leñosa mezclada con salvado o higos chumbos, por su alto valor nutritivo, solía destinarse también al ganado de cerda. Se aprovechaba igualmente la leña procedente de las podas: la más gruesa (del mismo modo que la cáscara leñosa de la almendra), para calentar los hogares, y las ramas más finas, junto con otros restos de cultivos, malezas y otras ramas que no se usaban como combustible, podían emplearse para la realización de hormigueros que contribuían a la fertilización del suelo. Era, no obstante, la cáscara exterior del fruto (ya fuera en verde o reducida en cenizas) el producto que por su alto valor potásico resultaba más eficiente para devolver a la tierra parte de los nutrientes consumidos por el mismo cultivo. En suma, una multiplicidad de aprovechamientos que, a pesar de que en las economías de base orgánica quedaran normalmente al margen de los circuitos comerciales, resultaban fundamentales, como también sucedía con otros cultivos leñosos, para asegurar su capacidad reproductiva; sobre todo en las áreas mediterráneas que no se caracterizaban, precisamente, por la frondosidad de sus bosques o la abundancia de baldíos para el pastoreo ${ }^{14}$. Un punto sobre el que ya llamaron la atención, en el caso de Mallorca e Ibiza, diversos autores:

«El agricultor guiado por el interés ha evolucionado hacia el cultivo arbóreo [...] almendro, olivo, higuera, algarrobo principalmente. Supeditando á estos, el de la alternativa de tres o cuatro hojas y tendiendo siempre hacia la transformación de las tierras de alternativa en prédios de arbolado [...] Esto trajo consigo la restricción en el número de cabezas de ganado mayor [...] puesto que no solo disminuyen los forrages, sino que la plantación de arboles en los prédios impide su acceso a los mismos [...] En cambio el menor se beneficia con los productos secundarios de dicho arbolado y algunos principales [...] Esta constatación nos hace ver que no se puede condenar en absoluto esta transformación de la agricultura regional en lo que á la industria pecuaria se refiere» (Ballester, 1912: 4$5)$.

\section{EL CULTIVO ANTES DE LA EXPANSIÓN MASIVA, 1780-1900}

En la islas, al igual que en otras regiones de clima mediterráneo, el almendro era conocido desde la Antigüedad y su fruto se destinaba tanto a usos culinarios como medicinales.

14. Intante-Amate et al. (2014); Infante-Amate e Iriarte-GoÑ (2017); Iriarte-GoÑ (2013); IRIARTE-GOÑI y AYUdA (2006); SOTO (2015). 
Sin embargo, hasta principios del siglo xx, los datos sobre extensión superficial y producción de almendras son fragmentarios. En el caso concreto de Baleares, por ejemplo, no disponemos de información seriada hasta 1860 .Y ello, a pesar de que desde los siglos XVII y XVIII está documentada la exportación de almendras hacia distintos mercados nacionales e internacionales (Barcelona, Cádiz, Cagliari, Génova, Livorno, Marsella, etc.), y a ciudades atlánticas como Ámsterdam que servía como plataforma de redistribución ${ }^{15}$. De todos modos, parece que fue sobre todo en el último tercio del setecientos, con el apoyo de la Sociedad Económica de Amigos del País (SEMAP), cuando se impulsó la diversificación arbórea en general y el cultivo del almendro en particular ${ }^{16}$. Esta difusión inicial se vió favorecida por la crisis que desde finales del siglo XviII afectaba al olivar y por la posibilidad, como sucedía con el olivo, de asociar el almendro con los herbáceos; principalmente con los cereales que en las islas siempre escaseaban. En cualquier caso, hasta mediados del siglo XIx, el olivo, mayoritariamente localizado en las explotaciones de mayor tamaño de la sierra Norte de Mallorca (Muntanya), continuó siendo el árbol predominante del paisaje agrario, y el aceite el principal producto de exportación ${ }^{17}$.

La mayoría de los estudios sobre la estructura de la propiedad isleña relacionan la diversificación arbórea con la parcelación de la gran propiedad ${ }^{18}$. Entre otras razones, porque hasta la publicación definitiva de la abolición de vínculos (1841), el acceso a la tierra de las familias campesinas estaba constreñido por las leyes fideicomisarias y las restricciones que pesaban sobre la parcelación y el establecimiento de tierras. Lo que explica, en cierto modo, que la aceleración de la difusión del cultivo coincida con el proceso de parcelación de las grandes propiedades iniciado en el segundo tercio del ochocientos a raíz de la reforma agraria liberal ${ }^{19}$. Sin embargo, interesa subrayar que las grandes propiedades agrarias no se mantuvieron al margen de la introducción del almendro ni de la comercialización del fruto. El descenso de la rentabilidad del olivar y la crisis de los mercados internacionales contribuyeron a la sustitución de los olivos por nuevos cultivos arbóreos en las tierras de mayor calidad y, en un número significativo de grandes explotaciones, la almendra constituirá, hasta la década de 1960, una de las principales fuentes de ingresos ${ }^{20}$.

15. BibILONI (1995: 98); MANERA (2001: 129-130).

16. Jover y MANERA (2009: 476-477, 491); MANERA (2014: 166-183); MOLL (2008: 297-99).

17. Bisson (1977); Juan (1980); Daviu (1983); Morey y Molina (2016).

18. SATORRAS (1883: 11).

19. Canut (1865); Habsburg-Lorena (1982-1993: vol. 5, 33-34); Barceló (1964); Bisson (1977); Cela (1979); Moll y Suau (1979); Rosselló (1982); Suau (1991); Morey (1999, 2018); JOVER y MOREY (2003); MOREY y JOVER (2018).

20. Así se pone de manifiesto en algunos libros de contabilidad: Son Vivot d'Inca (Albertí \& Morey, 1986), Son Torrella de Santa Maria y otras propiedades (Morey, 2013, 2019), Ca s’Hereu 


\section{CUADRO 2}

Evolución de la superficie de almendral

y de la producción de almendra en Baleares, 1860-1902

\begin{tabular}{lccc}
\hline Año & Superficie (ha) & Producción almendra $(\mathbf{Q m})$ & Valoración (ptas. corrientes) \\
\hline 1860 & 5.961 & 41.551 & 824.828 \\
1875 & 6.530 & 43.985 & 834.344 \\
1883 & 7.600 & 48.670 & 1.059 .343 \\
1902 & 8.500 & 170.000 & - \\
\hline
\end{tabular}

Fuente: elaboración propia a partir de las memorias regionales y la estadística de 1902 (Grupo de Estudios de Historia Rural, 1991).

La forma como se realizaron las parcelaciones favoreció la expansión del almendro en las pequeñas explotaciones. La subdivisión de la gran propiedad se llevó a cabo, mayoritariamente, a través del establecimiento enfitéutico o la venta a censo, que obligaba a los adquirientes al pago de una entrada inicial y de sucesivas cuotas anuales, cuyo impago podía suponer la pérdida de la propiedad y de todas las mejoras realizadas desde el momento de la adquisición. Esta modalidad ayuda a entender, en la práctica, que las familias que habían podido acceder a la propiedad de pequeñas parcelas no escatimaran esfuerzos -sobre todo en trabajo- para poner en explotación unas tierras que eran, en muchos casos, de mediana o baja calidad; lo que explicaría a su vez la extensión del almendro en terrenos marginales. En este contexto, dada la rusticidad del árbol, su compatibilidad con los distintos tipos de terrenos ${ }^{21}$ y sus múltiples aprovechamientos, el cultivo acabó por generalizarse ${ }^{22}$.

Otra ventaja a menudo esgrimida para explicar la expansión del cultivo es la mayor rentabilidad económica del almendro frente a otros árboles. En 1865 se estimaba que una hectárea plantada de almendral podía reportar alrededor del $47 \%$ del total de la inversión y que los gastos del cultivo eran solo ligeramente superiores a los de la higuera; otro árbol que por sus variados aprovechamientos resultó también crucial para las economías campesinas $^{23}$. El Cuadro 3 recoge los ingresos netos proporcionados por los nuevos cultivos arbóreos y evidencia que el almendro se encontraba arraigado, sobre todo, en los alrededores de la capital (Palma).

de Son Servera (Archivo Ventura Rubí) o Els Pagos de Porreres (Archivo Villalonga-Mir).

21. SATORRAS (1878).

22. La cesión enfitéutica implica solo el traspaso del dominio útil y obliga a los adquirientes al pago de una cuota de entrada, un censo anual y, en ocasiones, reconoce al propietario directo una serie de derechos de origen feudal en pleno siglo XX (MOREY \& JOVER, 2018).

23. HabSBURG-Lorena (1959: 121). 


\section{CUADRO 3}

Extensión superficial de los nuevos cultivos arbóreos en 1865 y estimación en pesetas corrientes de los ingresos netos por hectárea plantada

\begin{tabular}{lccccccccr} 
& \multicolumn{3}{c}{ ALMENDRO } & \multicolumn{3}{c}{ HIGUERA } & \multicolumn{3}{c}{ ALGARROBO } \\
\hline Partido & Neto & N. ${ }^{0}$ árboles & ha & Neto & N. ${ }^{~}$ árboles & ha & Neto & N. ${ }^{~}$ árboles & ha \\
\hline Palma & 74,08 & 390.229 & 3.453 & 60,75 & 141.481 & 2.744 & 37,17 & 230.778 & 4.525 \\
Inca & 69,73 & 168.136 & 1.489 & 43,25 & 298.021 & 5.844 & 43,95 & 120.188 & 2.357 \\
Manacor & 47,05 & 115.261 & 1.020 & 52,25 & 216.369 & 4.243 & 30,85 & 37.167 & 729 \\
Medias y totales & 54,61 & 673.626 & 5.962 & 52,08 & 655.871 & 12.831 & 37,32 & 388.133 & 7.611 \\
\hline
\end{tabular}

Fuente: elaboración propia a partir de Habsburg-Lorena (1959: 103-130).

La crisis de la filoxera, cuya enfermedad motivó a partir de 1891 la recesión de los viñedos mallorquines y el cese de los negocios relacionados con la exportación de vino a Francia, se ha relacionado igualmente con el auge del almendro en las pequeñas explotaciones. Tradicionalmente se dio por supuesto que la enfermedad favoreció exclusivamente la expansión de este árbol. Sin embargo, otros estudios más recientes sugieren que los pequeños campesinos optaron incialmente por los cereales y las leguminosas y, en todo caso, por practicar un policultivo arbóreo con el objetivo de evitar situaciones de dependencia como las que se habían producido en torno al cultivo de la viña ${ }^{24}$.

\section{LAS VENTAJAS DE LA ESPECIALIZACIÓN TEMPRANA, 1900-1960/1970}

Desde finales del siglo XIX hasta el primer tercio de la siguiente centuria, la almendra balear gozó de una buena acogida comercial. La mayor parte se exportaba (en cáscara o en pepita) a Alicante y Valencia para la producción de peladillas y otros dulces, y en las islas se elaboraba también una cantidad significativa de aceite que se expedía mayoritariamente a América a través de distintos puertos peninsulares ${ }^{25}$. Las especiales características de las variedades cultivadas -la mayoría autóctonas- parecen estar en la base de la buena aceptación del fruto. Inicialmente la almendra destinada a la venta se agrupaba en tres grandes categorías dependiendo de la dureza de la cáscara ${ }^{26}$ : fuerte, floja (mollars) y semi-floja (semi-mollars), y, dentro de cada grupo, se priorizaban las variedades que producían mejores rendimientos. Los autores coetáneos ofrecen información detallada sobre dichas categorías y los precios medios de las variedades más cotizadas ${ }^{27}$. Observamos

\footnotetext{
24. PASTOR (2016: 62-67).

25. Carretero (1875); Habsburg-Lorena (1959: 123).

26. Fornés, Socias y Alonso (2019).

27. BALlester (1910).
} 
(Cuadro 4) que la variedad mejor pagada era la denominada fita, caracterizada por tener una sola pepita. Su cultivo exigía terrenos cálidos y poco ventosos y era propia de Ibiza. Venía, a continuación, la almendra mollar, cuya cáscara podía romperse fácilmente con los dedos. Estas no requerían unas condiciones climatológicas tan estrictas como las primeras, pero en plantación regular eran también exclusivas de dicha isla. En Mallorca, en cambio, prácticamente toda la almendra destinada al comercio era de cáscara dura; la mayoría se englobaba dentro de la categoría de corrientes $\mathrm{y}$, alrededor de una tercera parte, bajo el genérico de almendras finas ${ }^{28}$. Estos aspectos eran bien conocidos por los payeses, que extremaban las precauciones en el momento de la recolección del fruto y su posterior selección para la venta ${ }^{29}$.

\section{CUADRO 4}

Distribución de la almendra por categorías comerciales, 1910

\begin{tabular}{lcc}
\hline Tipología & \% comercializado & Ptas. corrientes Qm \\
\hline Fita & 9 & 79 \\
Mollar & 2 & 69 \\
Pou y clases finas & 24 & 60 \\
Corriente & 65 & 51 \\
\hline
\end{tabular}

Fuente:Ballester (1910: 52).

La buena acogida del fruto, junto con los factores anteriormente mencionados, determinarán que, a partir de los primeros decenios del siglo $\mathrm{xx}$, la almendra vaya asumiendo el papel comercial que años atrás había jugado el vino en las pequeñas explotaciones. Solo que a diferencia de lo que había sucedido con la viña, muy circunscrita a unas áreas concretas, el almendro se extenderá a prácticamente todos los municipios y comarcas de Mallorca y a buena parte de la isla de Ibiza. Según las cifras sobre distribución regional de cultivos de 1902 (Cuadro 5), a las Baleares le corresponden 8.500 ha de almendral, aunque según los datos recopilados en diversas memorias locales la cifra podría llegar a 10.000 $\mathrm{ha}^{30}$. En cualquier caso, dejando de lado las discrepancias entre las estadísticas nacionales y regionales, la constatación más relevante es que las islas figuran como la primera región española en hectáreas cultivadas y la segunda en producción después de Tarragona ${ }^{31}$.

28. Destacaban las denominadas de Son Pou o Pou de Felanitx por el hecho de cultivarse, principalmente, en ese termino municipal y en otros limítrofes (BALlESTER, 1910; CARRETERO, 1875).

29. Se subrayaba, sin embargo, la necesidad de introduir mejoras en la comercialización debido a la práctica generalizada de vender las almendras con cáscara a comerciantes especializados (BALLESTER, 1910: 45).

30. CARretero (1875).

31. Su buena posición se debe a que inicialmente se cultivó en regadío, de forma dispersa y en tierras de buena calidad. No obstante, el almendro quedará posteriormente en un segundo plano (muy 
Dicha constatación cobra todavía más relevancia si observamos que en la práctica solo cuatro provincias, todas de clima templado, controlaban más de las tres cuartas partes de la producción nacional, mientras que en el norte y el centro peninsular, debido a la importancia que tenían las condiciones ambientales y climatológicas para el cultivo, su presencia era prácticamente testimonial, pues, a pesar de que el almendro resistía bien las sequías, era muy sensible a las bajas temperaturas, sobre todo en las épocas de floración y fructificación ${ }^{32}$. Para asegurar su crecimiento, principalmente entre finales de invierno y principios de verano, el árbol necesitaba un cierto nivel de humedad, mientras que la fructificación de la almendra requería de un tiempo seco y soleado. Estos condicionantes se daban, sobre todo, en las comarcas del Mediterráneo español y en algunas regiones de otros países próximos, como Italia y Marruecos, con los que por entonces competía la almendra española.

\section{CUADRO 5}

Principales áreas nacionales productoras de almendra, 1902

\begin{tabular}{lrrrr}
\hline Provincias & $\mathbf{Q m}$ & ha & \% Qm & \% ha \\
\hline Tarragona & 177.000 & 8.200 & 23,20 & 19,80 \\
Baleares & 170.000 & 8.500 & 22,28 & 20,53 \\
Almería & 134.200 & 6.100 & 17,59 & 14,73 \\
Alicante & 100.300 & 5.900 & 13,14 & 14,25 \\
Murcia & 58.000 & 2.900 & 7,60 & 7,00 \\
Lérida & 18.700 & 1.700 & 2,45 & 4,11 \\
Cádiz & 17.670 & 930 & 2,31 & 2,25 \\
Canarias & 15.950 & 1.450 & 2,09 & 3,50 \\
Málaga & 14.060 & 703 & 1,84 & 1,70 \\
Huesca & 14.000 & 2.000 & 1,83 & 4,83 \\
Otras & 43.243 & 3.025 & 5,67 & $\mathbf{7 , 3 1}$ \\
TOTAL & $\mathbf{7 6 3 . 1 2 3}$ & $\mathbf{4 1 . 4 0 8}$ & $\mathbf{1 0 0 , 0 0}$ & $\mathbf{1 0 0 , 0 0}$ \\
\hline
\end{tabular}

Fuente: elaboración propia a partir de la estadística agraria de 1902 (Grupo de Estudios de Historia Rural, 1991).

La importancia de las Baleares dentro del conjunto nacional se fue afianzando durante el primer tercio del siglo Xx hasta el punto de que, durante la guerra civil española (19361939), la almendra se convierte en la principal fuente de obtención de divisas. Ello ex-

por debajo del avellano) y no recuperará posiciones hasta la década de 1970 (CARDó, 1983: 173175).

32. La flor no soporta, generalmente, temperaturas inferiores a $-3^{\circ} \mathrm{C} y$, en su etapa inicial, el fruto puede echarse a perder cuando estas se aproximan a $-1{ }^{\circ} \mathrm{C}$ (RuBí, 1980; Socias \& RALlo, 1996). 
plica el interés del régimen franquista por este producto y la confección de numerosas estadísticas sobre producción estimada y real, recuentos de árboles en producción por municipios y relaciones de precios oficiales. Gracias a ello disponemos de una visión de conjunto sobre la distribución del almendral en 1942 para Mallorca, Ibiza y Formentera. Con todas las precauciones hacia las estadísticas de la época, permite constatar que con respecto a $1914(38.500 \mathrm{ha})^{33}$ el incremento fue de más del $65 \%$, ya que se estima que alcanzó las 63.582 ha. Por zonas, destaca su avance en el partido de Inca (de 5.000 a 15.535 ha), mientras que en los de Palma y Manacor, donde la expansión se había iniciado previamente, el avance es de 4.000 y 5.500 ha, respectivamente. La información sobre los árboles de menos de cinco años permite constatar que en los años anteriores a la Segunda Guerra Mundial (1939-1945) ${ }^{34}$, la expansión fue firme en toda la provincia ${ }^{35}$. Como media, el número de árboles que todavía no habían entrado en producción se establece en torno al $15 \%$. Sin embargo, el incremento de Ibiza es superior al de cualquier zona de Mallorca: se sitúa cuatro puntos por encima de la media y prácticamente duplica la extensión de 2.500 ha recogida en memorias anteriores.

\section{CUADRO 6}

Extensión superficial por zonas y número de árboles correspondientes a las islas de Mallorca, Ibiza y Formentera, 1942

\begin{tabular}{lrrrrrrrrr}
\hline \multicolumn{2}{c}{ Partido judicial } & \multicolumn{2}{c}{ Árboles de menos de $\mathbf{5}$ años } & \multicolumn{2}{c}{ Árboles de más de $\mathbf{5}$ años } & \multicolumn{2}{c}{ Total almendros } & \multicolumn{3}{c}{ Superficie } \\
& Número & $\%$ & Número & $\%$ & Número & $\%$ & ha & $\%$ \\
\hline Palma & 391.998 & 15,45 & 2.145 .554 & 84,55 & 2.537 .552 & 32,28 & 20.326 & 31,97 \\
Inca & 322.598 & 16,88 & 1.588 .850 & 83,12 & 1.911 .448 & 24,32 & 15.535 & 24,43 \\
Manacor & 328.506 & 12,98 & 2.203 .131 & 87,02 & 2.531 .637 & 32,21 & 20.567 & 32,35 \\
Ibiza & 169.084 & 19,40 & 702.413 & 80,60 & 871.497 & 11,09 & 7.084 & 11,14 \\
Formentera & 466 & 5,38 & 8.203 & 94,62 & 8.669 & 0,11 & 70 & 0,11 \\
TOTAL & $\mathbf{1 . 2 1 2 . 6 5 2}$ & $\mathbf{1 5 , 4 3}$ & $\mathbf{6 . 6 4 8 . 1 5 1}$ & $\mathbf{8 4 , 5 7}$ & $\mathbf{7 . 8 6 0 . 8 0 3}$ & $\mathbf{1 0 0 , 0 0}$ & $\mathbf{6 3 . 5 8 2}$ & $\mathbf{1 0 0 , 0 0}$ \\
\hline
\end{tabular}

Fuente: elaboración propia a partir de Mestre (1942: 34-35).

El análisis de la evolución de la superficie cultivada en las islas en comparación con la trayectoria de otras provincias (Gráfico 1), evidencia su precocidad en el despegue y su re-

33. BALlester (1914).

34. Entre 1940-1944 se exportan $108 \mathrm{Tm}$ frente a las 20.750 correspondientes al periodo de la guerra civil (CELA, 1979: 47).

35. En 1940 la representación porcentual de las islas sobre el total español continúa siendo significativa: $26,39 \%$ en extensión, $17 \%$ en número de árboles y $23 \%$ en producción $(A E A, 1940: 223)$. 
levancia dentro del conjunto nacional ${ }^{36}$. Observamos, asimismo, que a mediados de 1960, el cultivo estaba todavía muy concentrado en las provincias del Mediterráneo consideradas como áreas de producción tradicional ${ }^{37}$. Las Baleares seguían controlando prácticamente un tercio de la extensión total.Venían, a continuación, las provincias del Levante (Alicante y Murcia con cerca del 15\%, respectivamente, y Castellón con un 6\%,) y Andalucía Oriental (donde destacaba Granada con más del 8\%). La representación en el resto del territorio nacional era todavía muy reducida; incluso en las regiones que a partir de 1970-1975 destacarán como áreas de nueva producción: Huesca y Zaragoza en Aragón, Lérida y Tarragona en Cataluña, Almería y Málaga en Andalucía Oriental, y Valencia en el Levante, por citar solo las principales.

\section{GRÁFICO 1}

Evolución de la superficie del almendral balear en comparación con otras provincias españolas, 1900-1975

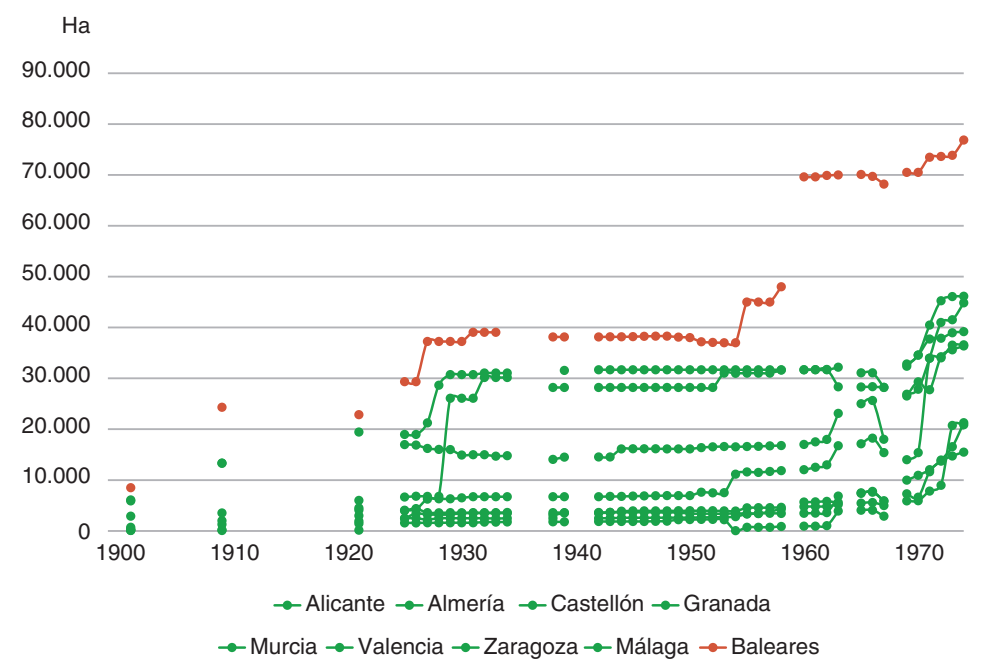

Fuente: elaboración propia a partir de los datos aportados por el Grupo de Estudios de Historia Rural (1991) y los que figuran en los anuarios de estadística agraria (1928-1975).

36. Hasta 1950 las estadísticas estuvieron muy influenciadas por el interés de ocultación propio del primer franquismo, de ahí que en todas las provincias las cifras se repitan de forma sospechosa, lo que sugiere un cierto estancamiento. El propio Ministerio reconoció $(A E A, 1950)$ que los datos de 19391949 estaban infravolarados. Si se comparan con los que se difunden desde 1954 y con los de las memorias regionales, pueden dar lugar a confusiones. En Baleares, según el Censo Agrario Español de 1962, había 10.000 ha más de almendral de las que figuran en los anuarios de estadística agraria (CELA, 1979: 43).

37. Entre comienzos del siglo xx y 1965, su extensión pasó de 41.000 a 215.000 ha repartidas entre un número restringido de provincias: Baleares, Alicante, Castellón, Murcia, Granada, Málaga, Almería y, posteriormente, Zaragoza y Valencia (Gráfico 5). 
Las memorias provinciales subrayan la rápida y generalizada expansión del almendro, y algunos autores manifiestan incluso cierta preocupación por las consecuencias negativas de dicho avance sobre los rendimientos del almendro y de los cultivos herbáceos ${ }^{38}$. Sin embargo, con el tiempo, la mayoría tienden a minimizar dichos aspectos y recomiendan incrementar los cuidados del almendro. Consideran que las tareas que se le dedican son insuficientes y que están generalmente supeditadas al cultivo asociado, ya que aparte de la labranza del suelo y de las labores dispensadas a los herbáceos, anualmente solo se podaban, entrecavaban y escardaban un tercio de los almendros. En general, denuncian que se le dedican escasas labores en trabajo y que estas se concentran, sobre todo, en el período de la recolección. Las pequeñas explotaciones se servían, durante todo el año y prácticamente de forma exclusiva, del trabajo familiar, mientras que los grandes propietarios solo hacían importantes inversiones en trabajo durante los meses de agosto y septiembre. Un recurso, el de la mano de obra temporal, que se entiende por la pervivencia hasta mediados del siglo xx de fuertes desigualdades en la distribución de la propiedad. En la práctica, el tamaño y la calidad de las tierras a las que habían accedido la mayoría de los campesinos resultaban insuficientes para asegurar la reproducción familiar. De ahí que algunos de sus miembros (principalmente mujeres y niños) se emplearan, al menos temporalmente, en las grandes explotaciones, donde en función del calendario agrícola de cada comarca participaban en la recolección de la almendra y otros frutos: algarrobas desde finales de septiembre y aceitunas a partir de los meses de octubre y noviembre ${ }^{39}$.

La expansión del cultivo se realizó siguiendo las formas tradicionales de manejo y prestando una especial atención a una cuestión que se consideraba prioritaria: la selección varietal. En primer lugar, por la coincidencia del periodo de floración con los meses de heladas más severas (enero y febrero), lo que podía disminuir notablemente la cosecha. Asimismo, dado que el almendro compartía la tierra con otros cultivos y ello contribuía a mermar los rendimientos de los árboles, era importante elegir las variedades más idóneas para practicar dicha asociación ${ }^{40}$. Desde la perspectiva de la polinización, la selección resultaba igualmente crucial, ya que las variedades comúnmente cultivadas no eran autofértiles (no podían fecundarse a sí mismas), lo que exigía la polinización cruzada. Este proceso, debido a la pesadez del polen, requería, en los sistemas de cultivo tradicional, de una doble condición: la convivencia en una misma parcela de variedades que florecieran a la vez y, al mismo tiempo, la presencia de insectos polinizadores (fundamentalmente abe$\mathrm{jas}^{41}$ ) que durante el periodo de floración garantizaran el transporte del polen entre las

38. BALlester $(1910,1914)$.

39. Jover (2014); Jover y Pujades (2020).

40. Mestre (1942: 7-12).

41. Rallo (1986). 
flores de las diferentes variedades. De ahí, precisamente, la importancia de que los procesos de polonización y fecundación transcurrieran cuando las temperaturas eran más favorables $^{42}$. Tradicionalmente la biodiversidad cultivada había sido también relevante, como hemos visto, desde el punto de vista comercial. Sin embargo, de la forma como figura la cotización de la almendra en las estadísticas oficiales publicadas por la Cámara de Comercio de las Baleares, se desprende que progresivamente desaparecen las clasificaciones comerciales por variedades. En 1942, por ejemplo, el ingeniero agrícola provincial se lamentaba de que a efectos comerciales la tipificación del producto no respetara la riqueza varietal ${ }^{43}$ y recomendaba extremar las precauciones en el momento de la recolección del fruto para evitar el desprestigio del producto local:

«Se caracteriza la almendra mallorquina por su extensa variedad, siendo dulce, sin mezcla de amargas, como sucede con el almendrón de varios de los demás centros productores. Dicha cualidad la hace ser muy estimada en todo el mundo para los usos de confitería, fabricación de Chocolates, etc, descollando en la industria local la de los turrones, de gran aceptación un tiempo en los paises americanos y Filipinas» ${ }^{44}$.

\section{LAS LIMITACIONES COMERCIALES DEL CULTIVO, 1960/1970-1990}

Desde mediados del siglo xx los agrónomos venían advirtiendo de las principales limitaciones del cultivo y de los moderados rendimientos del almendral balear, así como de la posición más modesta que en este ámbito ocupaban las islas en el contexto español. De hecho, así se desprende de la comparación de los rendimientos con la media nacional y con el comportamiento de otras provincias donde el árbol también se cultivaba en secano $^{45}$. Observamos, salvo en años muy concretos, y a diferencia de lo que sucede con la superficie cultivada, que las Baleares están en una situación de notable inferioridad ${ }^{46}$.

42. Fue en 1919 cuando el profesor Warren Porter Tufts difundió, en California, la autoincompatibilidad del almendro y enfatizó la necesidad de la polinización cruzada (Socias \& RALLO, 1996; FELIPE, 1988).

43. El producto comercial se clasificaba en seis categorías: propietario, escogido, gemelas, trozos, menudillo y vanas (MESTRE, 1942).

44. BCOCIN (1952: 76).

45. Los rendimientos anuales estaban muy influenciados, de todos modos, por las condiciones climatológicas de cada región. De ahí las advertencias que anualmente se incluían en los anuarios de estadística agraria sobre esta cuestión: «Los bruscos descensos de las temperaturas del mes de abril afectaron intensamente a la floración de los almendros, por lo cual su cosecha no fue abundante, un $20 \%$ menor que la de 1957; los rendimientos fueron deficientes en Alicante, Murcia, Huesca y Tarragona y medianos en Baleares» ( $A E A, 1958$ : $\mathrm{xx})$. 
Los autores coetáneos relacionaron dicha posición con el hecho de que los almendrales compartieran el terreno con los cultivos herbáceos, aunque reconocían que la asociación del cultivo no era ni mucho menos exclusiva del campo balear. En segundo lugar, con la mayor precocidad con la que el almendro se había introducido en las islas y el mayor número de árboles envejecidos que había en la provincia.Y, en tercer lugar, por la forma como se había expandido el cultivo, lo que había propiciado que en muchos terrenos se hubiera sembrado sin espaciarse convenientemente en perjuicio de su fructificación, lo que debilitaba el árbol y menguaba su resistencia a posibles enfermedades ${ }^{47}$.

\section{GRÁFICO 2}

Comparación de la evolución en Qm/ha de los rendimientos del almendral balear con otras áreas de producción nacional, 1939-2017

30

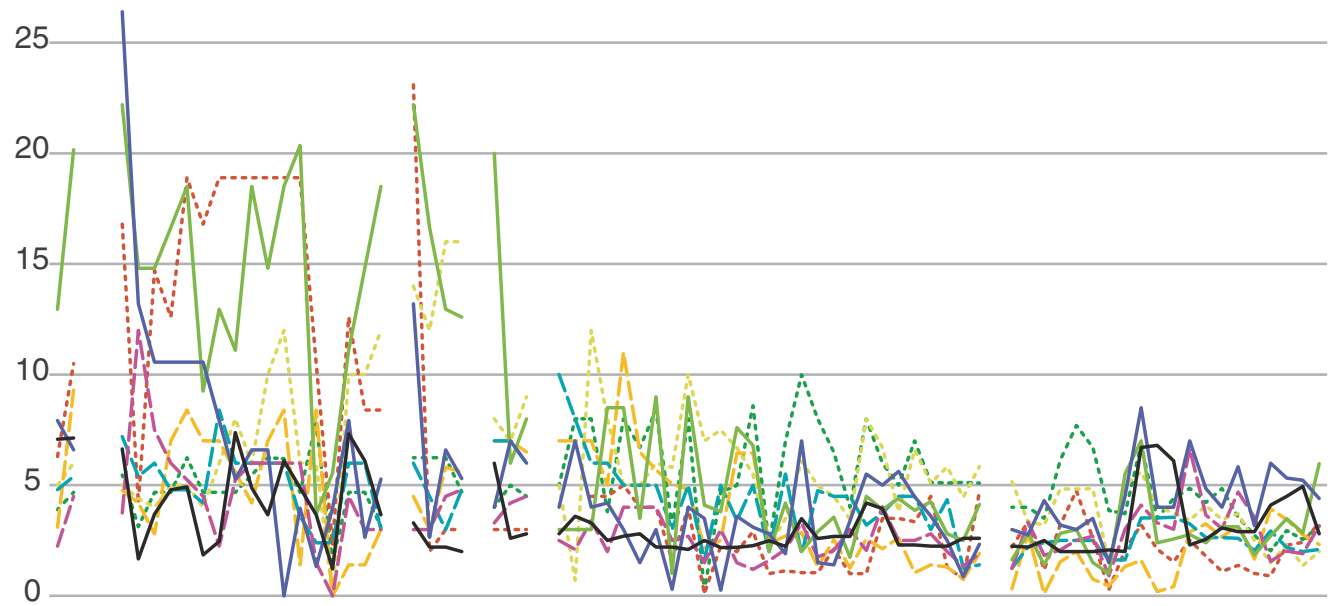

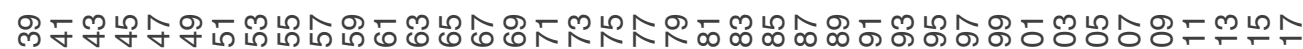

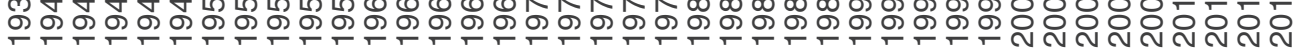

.... Alicante .... Almería .... Castellón -- Granada-- Málaga

-- Múrcia — Valencia — Zaragoza — Baleares

Fuente: elaboración propia a partir de los datos recogidos en los anuarios de estadística agraria (1939-2017).

46. Se han tomado en consideración los rendimientos de las principales regiones de producción tradicional: Alicante, Murcia, Castellón y Valencia en el Levante; Granada, Málaga y Almería en Andalucía Oriental; y Zaragoza en Aragón. En el Gráfico 2 solo se subraya, sin embargo, la evolución de Baleares, pues lo que se pretende es destacar la posición de la región objeto de estudio respecto del resto de las áreas productoras.

47. BCOCIN (1945: 113). 


\section{GRÁFICO 3}

Comparación de la evolución en Qm/ha de los rendimientos del almendral balear con la media nacional, 1939-2017

9

8

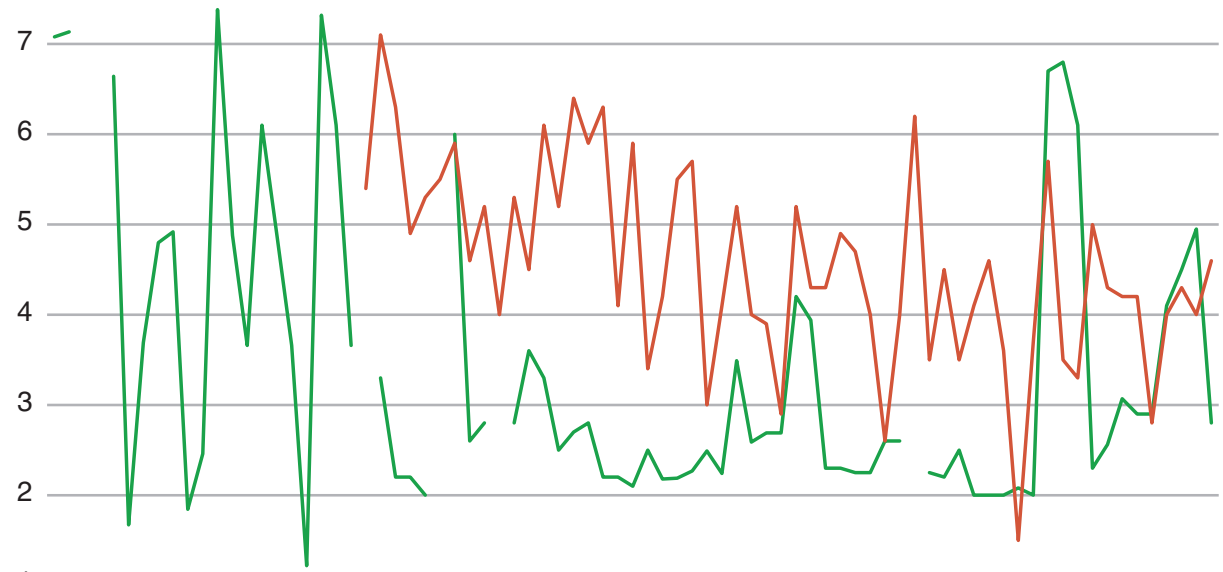

1

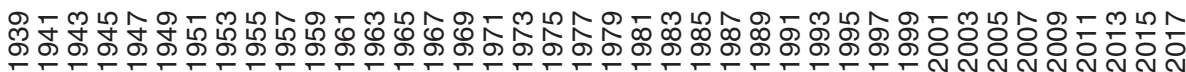

- Baleares — España

Fuente: elaboración propia a partir de los datos recogidos en los anuarios de estadística agrícola (1939-2017).

Los moderados rendimientos no desincentivaron, sin embargo, el cultivo del almendro, pues la superficie total cultivada en la región continuó incrementándose hasta los años noventa (Gráfico 6). Asimismo, los cambios en los hábitos alimentarios y la demanda creciente de un sector cada vez más amplio de la población, impulsaron al Gobierno español a fomentar distintos programas con el objetivo de incentivar el cultivo. Dichos programas, desarrollados desde los distintos servicios agronómicos provinciales, estuvieron vigentes hasta la segunda mitad de la década de los setenta y están en la base del incremento exponencial del cultivo en España (Gráfico 5) ${ }^{48}$. Contemplaban apoyo financiero para los agricultores, subvenciones para la compra de tierras, introducción de nuevas técnicas y ayudas a la exportación. En este contexto, la Jefatura Provincial de Baleares promovió un estudio para conocer los factores que dificultaban la competitividad de la re-

48. Entre 1970 y 1975 las hectáreas totales de almendral pasan de 298.700 a 500.000 y se produce el despegue del almendro en nuevas regiones productoras (MURUA, 1993: 7-8). 
gión ${ }^{49}$. Las conclusiones no aportaron cambios significativos respecto de lo que se venía reiterando: la escasa idoneidad de muchos de los terrenos en los que se había extendido, el hecho de que en la mayoría de las plantaciones no se dejara espacio suficiente entre los árboles, la continuidad del cultivo asociado, la insuficiencia de labores culturales, el bajo nivel de abonado, el deficiente sistema de poda y el desconocimiento de las enfermedades propias del árbol. Se concluyó, asimismo, que la edad y el mal estado vegetativo del almendral influía negativamente en la producción, ya que alrededor del $60 \%$ de los árboles tenía una edad superior a los cincuenta años y que solo una cuarta parte de ellos (el $21,44 \%$ ) presentaba un buen estado vegetativo ${ }^{50}$.

La necesidad de reducir la biodiversidad cultivada, es decir, las más de doscientas variedades que por entonces se estimaba que había en las islas, fue otra cuestión enfatizada por los agrónomos mallorquines. Entre otras razones, porque no siempre resultaban ser las más adecuadas para los distintos microclimas, lo que además de influir en la merma de la producción, repercutía también en la comercialización. Asimismo, porque el entremezclamiento de variedades había ocasionado una «mescolanza» de tal envergadura que obligaba a vender la almendra con el nombre comercial de "Mallorca propietario» ${ }^{51}$. Por ello, se recomendaba mejorar la red de comercialización, volver a recolectar por separado las variedades de mejor calidad y evitar que fueran otras áreas (especialmente Tarragona) ${ }^{52}$ las que se beneficiaran de la comercialización de la almendra producida en la región.

Las razones enumeradas incentivaron la puesta en marcha de un Plan de Mejora dividido en dos tipos de acciones. Unas de carácter inmediato (perseguían reducir en un $40 \%$ el almendral viejo y promover nuevas plantaciones) y otras, apoyadas en un conjunto de subvenciones cuya realización se preveía para el quinquenio 1968-1973, destinadas a modificar las formas tradicionales de cultivo. Sin embargo, a juzgar por los indicadores de los años posteriores, no todas las medidas tuvieron los resultados esperados. La superficie continuó expandiéndose (Gráfico 6) y, en algunos años concretos, los rendimientos incluso repuntaron. No obstante, la renovación del almendral no fue significa-

49. Pons y Simonet (1970); Gómez (1976).

50. Rubí (1980: 193).

51. Destacan las investigaciones desarrolladas desde el Centro de Investigación y Tecnología Agroalimentaria de Aragón (CITA) (FELIPE, 1997, 2000; FeliPE \& SociAs, 1994a, 1994b), el Instituto de Investigación y Tecnología Agroalimentarias de Cataluña (IRTA) y el Centro de Edafología y Biología Aplicada del Segura de Murcia (CEBAS-CSIC).

52. Gran parte de la almendra mallorquina se exportaba a través de Tarragona, donde la Lonja de Reus marcaba el precio del fruto y en la ciudad había una importante infraestructura para el descascarado y la selección de la avellana y la almendra (ARNAL, 2014: 28-29). 
tiva $^{53}$. Con respecto al sistema de cultivo, a pesar de la progresiva desaparición de los cereales para su cosecha en grano, continuaron sembrándose forrajes para el ganado. Esta disminución se explica, en parte, porque en una economía mercantilizada ya no resultaban indispensables para la autosubsistencia y, sobre todo, porque esta era una de las condiciones impuestas para poderse acoger a las subvenciones. Se insistía, asimismo, en la necesidad de incrementar el nivel de abonado, mejorar el sistema de poda e iniciar un proceso de sustitución de variedades autóctonas por otras importadas a las que se les atribuía una mayor productividad. Sin embargo, en la práctica, dichas medidas no consiguieron mejorar la competitividad del producto balear. Entre otras razones, por la evolución a la baja experimentada por el precio de la almendra desde mediados de la década de los setenta y la capacidad de los sectores económicos emergentes (el turismo y la construcción) para ofrecer unos salarios superiores a los del sector agrario ${ }^{54}$.

\section{GRÁFICO 4}

\section{Evolución del precio medio por kg de almendra percibido por los agricultores españoles en pesetas constantes de 1950}

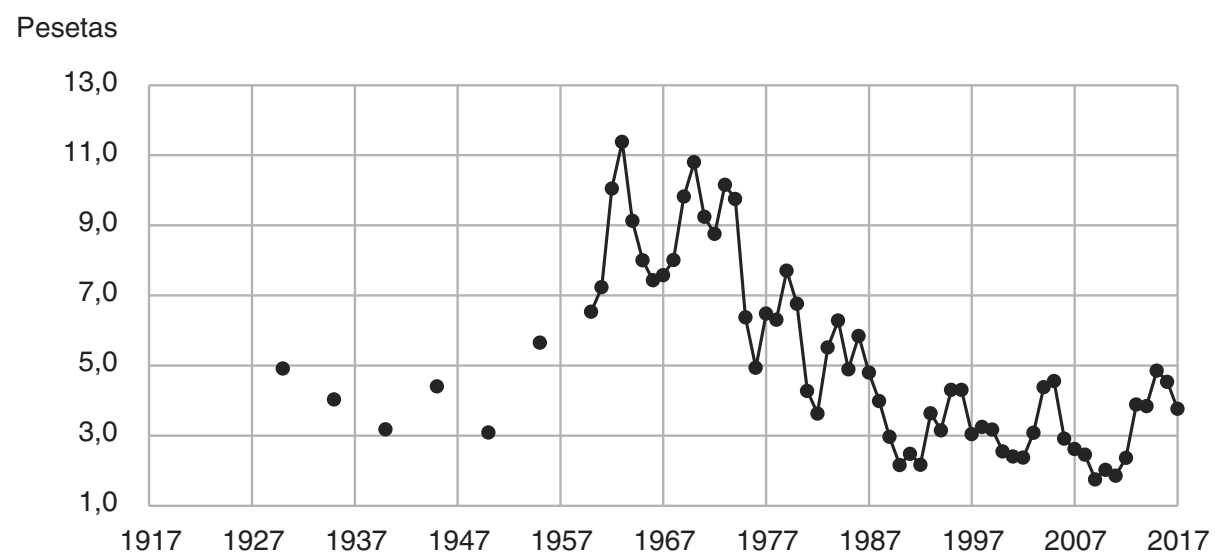

Fuente: elaboración propia a partir de los precios recogidos en los anuarios de estadística agraria deflactados según los índices de Maluquer (2013) hasta 2012 y posteriormente a partir del INE.

En cualquier caso, la recesión del cultivo -del mismo modo que su expansión- fue anterior en las grandes explotaciones que en las pequeñas unidades campesinas. De la com-

53. Entre 1964-1968 la extensión de almendral arrancado se calcula en 1.825 ha y las nuevas plantaciones realizadas entre 1964-1970 en 2.150 ha $(A E A, 1964-1970)$, mientras que el número total de almendros plantados entre 1965-1970 se estima en 361.915: alrededor del 5\% de los que entonces había en Mallorca (RuBí, 1980: 175).

54. Manera y Navinés (2018); Manera et al. (2019). 
paración de la extensión de las propiedades dedicadas al almendro en 1962 y $1980^{55}$ se desprende que en la década de los sesenta era el cultivo principal en más de un tercio de las propiedades con una extensión igual o superior a las cien hectáreas, mientras que en los ochenta se localizaba, sobre todo, en las pequeñas explotaciones surgidas de los procesos de parcelación, división y subdivisión de la propiedad. Las diferencias de comportamiento entre grandes y pequeños propietarios se explican, en primer lugar, por las diferentes formas en que ambos gestionaban y explotaban los almendrales, pues, mientras las pequeñas explotaciones no dependían para su cultivo de mano de obra jornalera, en las possessions la recolección del fruto se continuaba realizando a través de la contratación de un gran número de jornaleros y jornaleras, cuyos precios se encarecieron notablemente a partir de la década de $1960^{56}$. Asimismo, las explotaciones de mayor tamaño eran generalmente gestionadas de forma indirecta, lo que implicaba la repartición anual de los frutos del árbol y de los cultivos horizontales entre el propietario y el colono: normalmente dos tercios de la almendra para el primero y una tercera parte para el segundo, quien solía quedarse además con la mitad o la totalidad de la cosecha de los herbáceos ${ }^{57}$. Esta forma de proceder, a juzgar por las exploraciones de una muestra de contabilidades agrarias gestionadas por propietarios y arrendatarios, había resultado rentable para ambas partes. Los propietarios obtenían una cantidad monetaria anual y los colonos se aseguraban, al mismo tiempo, su participación parcial en los beneficios derivados de la comercialización del fruto y el aprovechamiento de las cosechas de los cultivos horizontales.

\section{LA PERVIVENCIA DEL CULTIVO EN LAS EXPLOTACIONES CAMPESINAS, 1990-2017}

El interés de los pequeños campesinos (la mayoría de edad avanzada) por mantener el cultivo está en la base de la pervivencia del paisaje del almendro, tanto en las islas como en otras áreas de producción nacional. Según el Censo Agrario de $1989^{58}$, la dimensión media de las explotaciones dedicadas a almendral no alcanzaba las tres hectáreas. Una situación que en las islas era, si cabe, todavía más acusada, ya que una cuarta parte de

55. Cela (1979: 43); Rubí (1980).

56. Así se desprende, por ejemplo, de la evolución de los salarios de las explotaciones de Ca s’Hereu de Son Servera (Quintana, 1979, 1981) y Son Macià Negre de Marratxí (BARCELÓ, 2003).

57. Bisson (1977: 235, 240-241). Esta forma de cesión ya había sido predominante en algunas fincas oleícolas durante los períodos en que el aceite gozó de una buena cotización (MOREY, Jover \& Villalonga, 2016).

58. Murua (1993: 18). 
ellas era inferior a una hectárea ${ }^{59}$. Ello dificultaba, sin duda, la rentabilidad económica y la introducción de la mecanización. De ahí que los pequeños campesinos mantuvieran los almendrales sin introducir variaciones sustanciales en las formas de cultivo y sin realizar, generalmente con el objetivo de evitar gastos, nuevas plantaciones ni arrancar los árboles viejos. Se centraron, sobre todo, en reponer las faltas y conservar un cultivo que, tal y como se seguía practicando, era compatible con otras actividades ${ }^{60}$; incluso con el turismo, ya que las inversiones en trabajo que se le dispensaban se realizaban en épocas muy concretas y la recolección del fruto se llevaba a cabo, en muchos casos, solo para obtener un complemento monetario. Una forma de proceder, sin duda, que ha contribuido a conservar la herencia cultural y a preservar el equilibrio ecológico en buena parte del territorio insular a pesar de la terciarización de la economía ${ }^{61}$.

En la pervivencia del paisaje del almendro hasta el presente siglo ha influido, asimismo, que a partir de los noventa pasara a ser un cultivo subvencionado. En una primera etapa mediante los planes de mejora de la calidad y de la comercialización a través de las organizaciones de productores de frutas y hortalizas y, posteriormente, a través de las ayudas directas de la PAC, que a partir de 2012 evolucionaron hacia un régimen de pago único y permitieron a los propietarios acogerse a una ayuda por superfície realizando unas prácticas culturales mínimas ${ }^{62}$. En cualquier caso, futuras investigaciones deberán profundizar en estos y otros aspectos relacionados con la situación actual. Por un lado, en las dificultades que tienen los campesinos que cultivan tierras que no son de su propiedad para conseguir contratos de uso de un mínimo de 25 años de duración, lo que les retrae, en su opinión, de emprender determinadas inversiones y, en particular, de realizar plantaciones arbóreas. Sin embargo, la evolución superficial del almendral balear durante el presente siglo ${ }^{63}$ permite plantear la hipótesis de que la acelerada regresión más reciente no responde, tanto a la pérdida del valor económico del almendro como a la expansión de una bacteria (Xylella fastidiosa) que, si bien no fue declarada oficialmente hasta 2016, a juzgar por la evolución de la superficie abandonada durante los años anteriores pudo haber empezado a actuar mucho antes; a pesar de que en un principio la regresión fuera atribuída al deterioro de las prácticas culturales. Por otra parte, según se desprende de las declaraciones de cultivos de la PAC entre 2004 y 2018 , en algunos muncipios de Ma-

59. En Baleares, solo el $18 \%$ de la superficie total del almendral se cultivaba en explotaciones superiores a las cinco hectáreas (RUBí, 1980: 135).

60. Estas prácticas se desprenden de las investigaciones de ForNÉs (2011), del proyecto subvencionado por el Ayuntamiento de Santa Margalida y de la Acción Especial (AAEE8/2014) auspiciada por el Govern de les Illes Balears y el Fondo de Desarrollo Regional de la Unión Europea (FEDER).

61. Marull et al. (2015, 2016, 2018); Tello et al. (2018); Murray et al. (2019).

62. Ruiz Pulpón et al. (2016); Larrubia y Natera (2016).

63. Manera y Navinés (2018); MANERA et al. (2019). 
llorca (Llubí, 46\%; Son Servera, 39\%; Sant Llorenç, 36,50\%; Muro, 35,67\%; Petra, $32,40 \%$; por citar solo los casos más evidentes) la reducción ha sido de tal envergadura que ha modificado por completo la fisonomía de su entorno ${ }^{64}$. Hasta el punto de que el paisaje tradicional solo parece resistir en áreas muy concretas y en un reducido número de municipios: Artà, Palma, Algaida, Felanitx, Santanyí, Calvià y Andratx.

\section{GRÁFICO 5}

\section{Evolución de la superficie de almendral} en España y de la producción de almendra, 1902-2017

ha

Qm

772.500

672.500
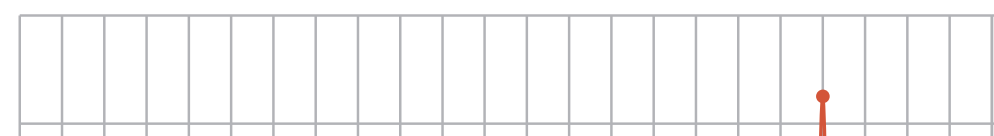

4.263 .000

3.763 .000

572.500

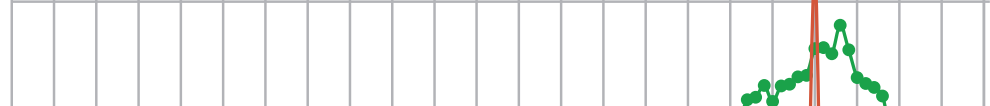

3.263 .000

472.500

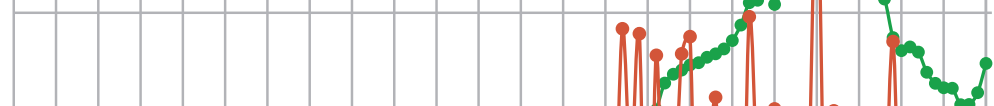

2.763 .000

372.500
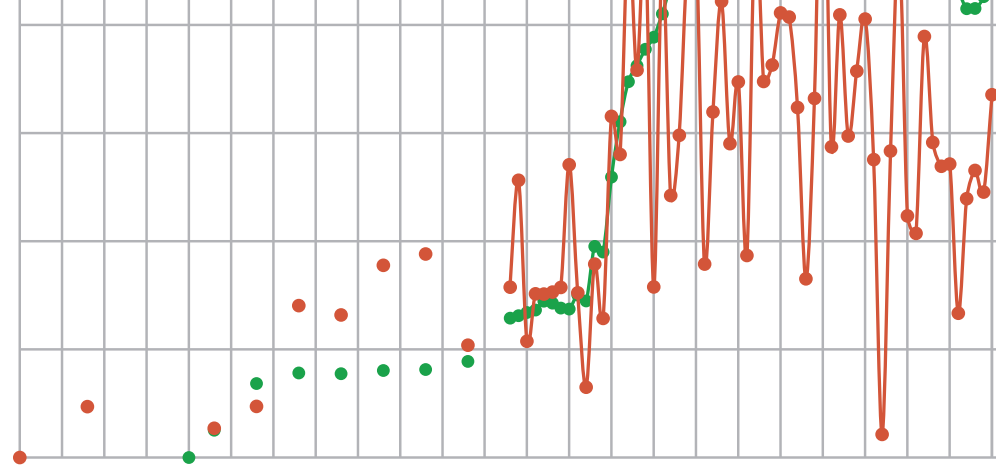

172.500

2.263 .000

272.500

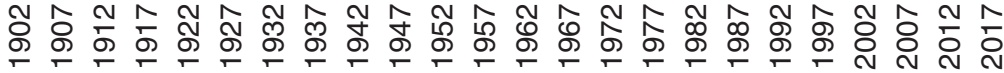

1.763 .000

1.263 .000

72.500

$\multimap$ Extensión (ha) $\multimap$ Producción (Qm)

Fuente: elaboración propia a partir de la recopilación estadística realizada por el Grupo de Estudios de Historia Rural (1991) y los datos que figuran en los anuarios de estadística agraria (1928-2017).

Asimismo, el análisis de la distribución regional del cultivo en España para 2016-2017, año en que se reconoce oficialmente la expansión de la citada bacteria en Mallorca y en el que concluimos nuestra aportación, pone de manifiesto que los cambios de localiza-

64. Datos obtenidos de la sistematización de las superfícies municipales de almendral según las solicitudes anuales de la PAC. 


\section{GRÁFICO 6}

Evolución de la superficie de almendral en Baleares y de la producción de almendra, 1902-2017

ha

Qm

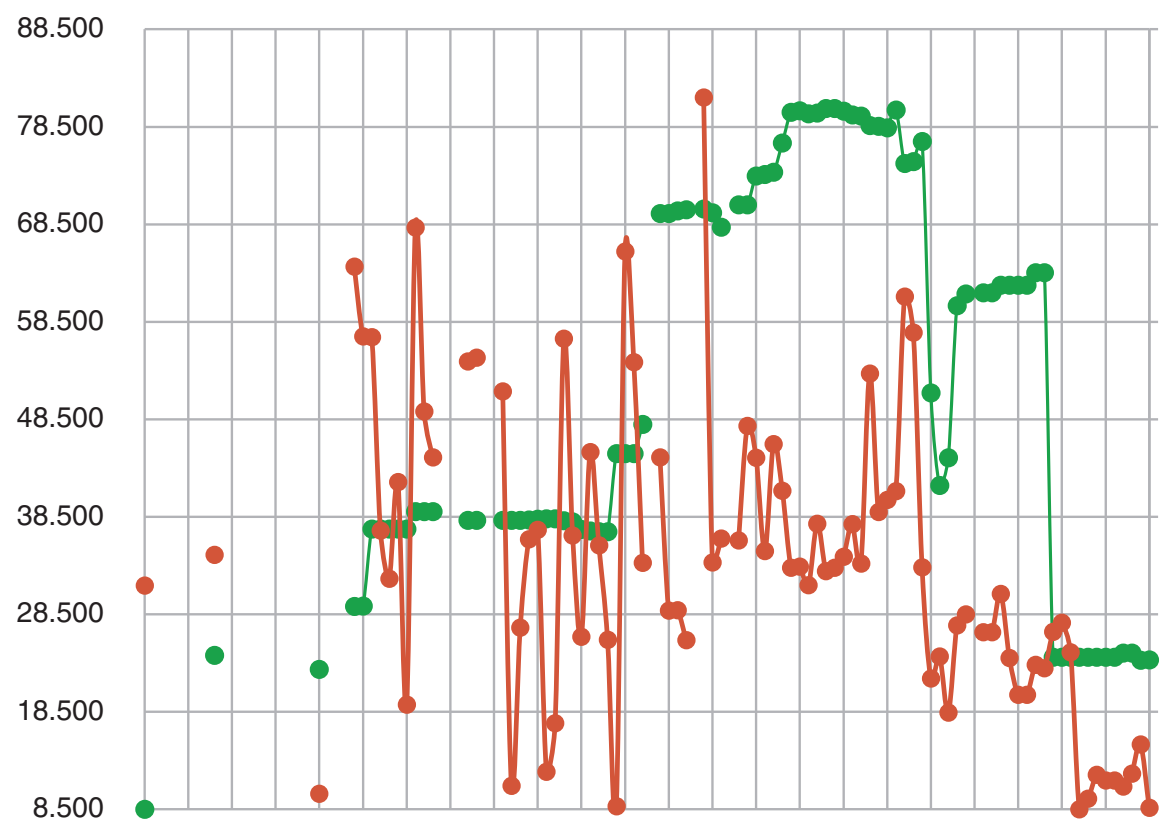

455.210

405.210

355.210

305.210

255.210

205.210

155.210

105.210

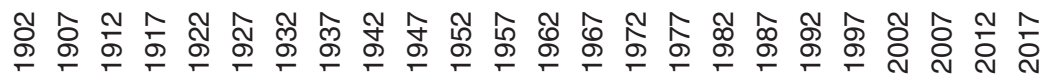

- Extensión (ha) —Producción (Qm)

Fuente: elaboración propia a partir de la recopilación estadística realizada por el Grupo de Estudios de Historia Rural (1991) y los datos que figuran en los anuarios de estadística agraria (1928-2017).

ción y de posicionamiento no han afectado exclusivamente a las islas ${ }^{65}$. El cultivo continúa siendo relevante en algunas áreas de producción tradicional, pero desde finales del siglo pasado en adelante han sido pocas las que han incrementado la superficie cultivada (de forma significativa Granada ${ }^{66}$ y Murcia ${ }^{67}$ ), pues la mayoría han registrado impor-

65. SOCIAS y COUCEIRO (2014).

66. Desde comienzos del presente siglo el primer puesto corresponde a la Comunidad Autónoma de Andalucía (VELASCO, 2016), seguida de la Región de Murcia y las comunidades de Valencia, Aragón, Castilla-La Mancha y Baleares (Aznar, Balmonte \& Velasco, 2016).

67. A partir del Reglamento de Ayuda Comunitaria de 1989, el repunte de la extensión del cultivo en secano fue considerable, produciéndose además un aumento de la superficie en regadío y el abandono del almendro en tierras marginales (ROMERo, MARTíneZ HERNÁNDEZ \& BELMONTE, 2012; GIL Meseguer, 2006; Gil MEseguer \& Gómez Espín, 2016). 
tantes reducciones: Baleares, Valencia, Alicante ${ }^{68}$, Almería, Castellón, Lérida y Tarragona, por citar solo las principales. Como contrapartida, gracias a la introducción de variedades de floración más tardía, el almendro ha ido ganando posiciones en algunas comunidades del interior peninsular (Castilla-La Mancha) ${ }^{69}$, donde por sus condiciones climatológicas y edafológicas, siguiendo las formas de manejo tradicional, no hubiera resultado viable. Desde esta perspectiva, resulta igualmente comprensible su importancia creciente en regiones como Zaragoza, Huesca, Albacete o Toledo y en algunas áreas de La Rioja. Estos cambios y, en definitiva, el mayor o menor arraigo del cultivo en las distintas regiones responde, en cada caso, a factores de muy distinta índole que exceden los objetivos de este artículo y sobre los que en un futuro sería interesante profundizar para establecer comparaciones con el caso balear.

\section{CONCLUSIONES}

La dilatada trayectoria del almendro en el campo balear nos ha llevado a considerar razones no estrictamente productivas o comerciales para entender tanto su expansión como su regresión. Entre las principales, el carácter multifuncional del cultivo y su capacidad para proveer a las economías campesinas de determinados productos (combustible, abono, pienso para el ganado, etc.) que resultaron cruciales para el reinicio de los ciclos productivos de muchas explotaciones, incluídas las de mayor tamaño. Desde esta perspectiva, la perpetuación del cultivo tradicional y, sobre todo, la resistencia a los cambios o las dificultades de afrontarlos con éxito debido a las características de la estructura de la propiedad isleña, están a la vez en la base de la preservación del paisaje del almendro, pues muchos pequeños campesinos, ya que en las grandes explotaciones el retroceso fue anterior, continuaron compatibilizando su cultivo con el ejercicio de otras actividades; muy especialmente con el trabajo relacionado con el turismo o la construcción a partir de 1960-1970.

Las políticas agrarias, inicialmente promovidas por el Gobierno español y posteriormente por la Comunidad Europea, han contribuído igualmente a dicha preservación, tanto en las islas como en el conjunto de España. Asimismo, el hecho de que a partir de 2012 las ayudas europeas evolucionaran hacia un régimen de pago único ha permitido mantener buena parte del almendro en secano. En las islas, el avance del cultivo en regadío con unas prácticas más intensivas no ha sido significativo. En cualquier caso, los

68. López Ortiz y Melgarejo (2016).

69. Llama la atención el caso de Albacete, donde entre 2014-2016 se plantaron 4.600.000 árboles y en 2017 la extensión total del cultivo ocupaba unas 60.000 ha (CONSEJERÍA DE AGRICULTURA, Medio Ambiente y Desarrollo Rural, 2016). 
planes de mejora productivistas aplicados desde 1960-1970 por el Servicio Agronómico Provincial a instancias del Gobierno español, además de no conseguir reactivar la productividad ni dotar al fruto de una mayor competitividad, tuvieron serias repercusiones medioambientales. Auspiciaron, por un lado, la eliminación del cultivo asociado que había permitido simultanear en una misma explotación las prácticas agrarias y ganaderas. Asimismo, fomentaron el cultivo en plantaciones regulares en detrimento del almendro en tierras marginales y diseminados donde, a pesar de sus más que moderados rendimientos, había contribuido a preservar la erosión del suelo. Por último, aunque no menos relevante, la importancia otorgada en dichos planes a la sustitución de muchas variedades autóctonas por otras importadas, nuevamente con el pretexto de incrementar los rendimientos y contribuir a la homogeneización del fruto, mermó significativamente la riqueza de la biodiversidad cultivada; otra de las singularidades del caso balear. No obstante, en el ámbito de la preservación de la riqueza varietal, las pequeñas explotaciones también han jugado un papel crucial que, a día de hoy, ha posibilitado avanzar hacia un cultivo menos intensivo o ecológico a partir de algunas variedades tradicionales y, a la vez, a su catalogación con el ánimo de poder disponer, en un futuro, de un banco de germoplasma.

\section{AGRADECIMIENTOS}

Este artículo se inscribe dentro del proyecto de investigación PGC2018-096350-B-100 otorgado por el MCIU y codirigido por R. Congost y E. Saguer (Universitat de Girona, Centre de Recerca d'Història Rural). Se ha beneficiado, asimismo, de una acción especial (AAEE8/2014) auspiciada por el Govern de les Illes Balears y el Fondo de Desarrollo Regional de la Unión Europea (FEDER). Una mención especial merece J. Grimalt por facilitarnos el acceso a diversas memorias reglamentarias del Servicio Agronómico Nacional (sección de Palma) y el Área de Ayudas Directas de la PAC del FOGAIBA perteneciente a la Consejería de Agricultura Pesca y Alimentación. Agradecemos la revisión crítica a los evaluadores anónimos de Historia Agraria, los comentarios realizados por E. Saguer y G. Jover y la ayuda recibida de A. Seguí, M. Ferrer y C. Rotger. Las aportaciones de todos ellos han enriquecido notablemente el resultado final.

\section{REFERENCIAS}

Albertí, A. \& Morey, A. (1986). El funcionament d'una possessió mallorquina al primer terç del segle xIx: Son Vivot del Puig d'Inca. Randa, (20), 5-45. 
Anuario de Estadística Agraria (AEA) (1904-2019). Madrid: Ministerio de Agricultura, Pesca y Alimentación (MAPA). https://www.mapa.gob.es/es/estadistica/temas/publicaciones/anuario-de-estadistica/default.aspx

ARnal, E. (2014). Els exportadors d'avellana: El cas dels Carnicer. Butlleti del Centre d'Estudis Selvatans, (8), 11-33.

Aznar, J. A., Balmonte, L. J. \& Velasco, J. F. (2016). Caracterización del cultivo del almendro en secano en Andalucía y propuestas de reconversión. ITEA, 112 (3), 317-335.

BALlester, A. (1910). Estudio de la riqueza que en Baleares representa la producción media anual de los árboles y arbustos frutales, tubérculos, raíces y bulbos deducida de los datos correspondientes al quinquenio 1905-1909. Ejemplar mecanografiado procedente del Servicio Agronómico Provincial.

BALleSter, A. (1912). Estudio de la riqueza que en Baleares representa la producción media anual de los pastos y forrages, otros aprovechamientos para la alimentación del ganado y las pequeñas industrias zoógenas anexas. Ejemplar mecanografiado procedente del Servicio Agronómico Provincial.

BALlester, A. (1914). Estudio de los antecedentes preliminares relativos al conocimiento de las condiciones en las que se desenvuelve el cultivo del cereal en España. Ejemplar mecanografiado procedente del Servicio Agronómico Provincial.

BAllester, A. (1922). Resumen estadístico de la producción agraria en Baleares. Ejemplar mecanografiado procedente del Servicio Agronómico Provincial.

BArCeló, A. (2003). Son Macià Negre (Marratxí): Miscel-lània històrica d'una possessió mallorquina. 3 vols. Ejemplares mecanografiados.

BARCELÓ, B. (1964). El segle XIX a Mallorca. Ciutat de Mallorca: Gràfiques Miramar.

BiBILONI, A. (1995). El comerç exterior de Mallorca: Homes, mercats $i$ productes d'intercanvi (1650-1720). Mallorca: El Tall.

Bisson, J. (1977). La terre et l'home aux Iles Baléares. Aix-en-Provence: Edisud.

Boletín de la Cámara de Comercio, Industria y Navegación de Palma (BCOCIN) (18991945). Palma: Cambra Oficial de Comerç, Indústria i Navegació de Palma de Mallorca.

CANut, B. (1865). Memoria sobre los medios de promover el incremento de la riqueza agrícola y pecuaria de Mallorca atendidos los recursos y las condiciones de su territorio. Palma: Imprenta de Felipe Guasp.

CARDó, J. (1983). L'evolució dels conreus en del Camp de Tarragona a partir del segle XVIII. Valls: Institut d'Estudis Vallencs.

CARreras, A. \& TAFunell, X. (Coords.) (2005). Estadísticas Históricas de España: Siglos XIX-XX. Bilbao: Fundación BBVA.

Carretero, E. (1875). Memoria sobre el estado de la agricultura en esta provincia. Ejemplar mecanografiado procedente del Servicio Agronómico Provincial.

CELA, C. J. (1979). Capitalismo y campesinado en la isla de Mallorca. Madrid: Siglo XXI. 
Consejería de Agricultura, Medio Ambiente y Desarrollo Rural (2016). Situación del almendro en Albacete. Gobierno de Castilla-La Mancha, Dirección Provincial de Albacete.

DaviU, G. (1983). La producció d'oli a la Mallorca del segle XviII. L'Avenç, (32), 49-53.

Estelrich, P. (1907). El almendro y su cultivo en el mediodía de España e Islas Baleares. Madrid: Hijos de J. Cuesta.

FeLIPE, A. J. (1988). Factores que influyen en la polinización del almendro. Quaderns agraris, (10), 65-80.

FELIPE, A. J. (1997). El almendro: Nuevas variedades. Vida rural, (46), 35-36.

FeLIPE, A. J. (2000). Perspectivas sobre el cultivo del almendro. Horticultura: Revista de industria, distribución y socioeconomía horticola: Frutas, hortalizas, flores, plantas, árboles ornamentales $y$ viveros, (142), 16-22.

FELIPE, A. J. \& SociAs, R. (1994a). El almendro en España: La importancia de la mejora genética de variedades. Vida rural, (11), 64-67.

Felipe, A. J. \& Socias, R. (1994b). Variedades de almendro: Descripción y datos de las más importantes. Vida rural, (5), 76-82.

FlORIT, F. (1983). Les transformacions del paisatge rural $i$ de la propietat de la terra a la comarca del Pla de Mallorca (s. XIX-XX). Tesis doctoral. Palma: Universitat de les Illes Balears.

Fornés, J. (2011). El cultiu de l'ametler a Mallorca. Memoria de investigación. Palma: Universitat de les Illes Balears.

ForNÉs, J., SociAs, R. \& Alonso, J. M. (2019). La dureza de la cáscara y el rendimiento en pepita de la almendra. Revista de fruticultura, (68), 19-29.

Garrabou, R. \& GonZÁlez de Molina, M. (Eds.) (2010). La reposición de la fertilidad en los sistemas agrarios tradicionales. Barcelona: Icaria.

Gil Meseguer, E. (2006). Los paisajes agrarios de la región de Murcia. Papeles de Geografía, (43), 19-30.

Gil Meseguer, E. \& Gómez Espín, J. M. (2016). Impactos territoriales de la Política Agraria Común en almendro, olivar y viñedo de vinificación de la Región de Murcia. En A. R. Ruiz Pulpón et al. (Eds.), Treinta años de la Política Agraria Común en España: Agricultura y multifuncionalidad en el contexto de la nueva ruralidad (pp. 1527). Ciudad Real: Asociación de Geógrafos Españoles.

Gómez, E. (1976). Inventario del almendro en la isla de Mallorca: Avance de resultados. En I Congreso Internacional de Almendra y Avellana: (Reus: 25 al 28 de octubre de 1976) (pp. 603-622). Reus: Feria Oficial de Muestras de la Provincia de Tarragona.

GonzÁlez de Molina, M., Infante-Amate, J. \& Guzmán Casado, G. (2014). Del manejo tradicional al manejo orgánico del olivar: Aplicaciones prácticas del conocimiento histórico. Revista de Historia, (70), 37-68. 
Grasset de Saint-Sauveur, A. (1952 [1801-1803]). Viaje a las islas Baleares y Pithiusas. Palma: Roda.

GRAU, E. (1981). El conreu de l'olivera a Mallorca a mitjan segle XIX: Sistema de conreu, rendiments $i$ productivitat segons les dades de l'interrogatori fiscal de 1850-51. Tesina inédita. Barcelona: Universidad de Barcelona.

GrAU, E. \& Tello, E. (1985). Anàlisi de la producció agrària mallorquina en els seus dos sectors fonamentals: L'oli i els cereals. Randa, (18), 46-91.

GRUPO DE Estudios DE Historia RuRAL (1991). Estadísticas históricas de España, 18951935. Madrid: Ministerio de Agricultura, Pesca y Alimentación.

HABSBURG-LoRenA, L. S. (1959). Las Baleares, descritas por la palabra y el grabado: $M a-$ llorca agrícola (primera mitad). Palma: Imprenta Mossèn Alcover.

Habsburg-Lorena, L. S. (1982-1993). Las Baleares por la palabra y el grabado. Palma: Caja de Ahorros de Baleares «Sa Nostra».

INFANTE-AMATE, J. (2012a). "Cuántos siglos de aceituna»: El carácter de la expansión olivarera en el sur de España (1750-1900). Historia Agraria, (58), 39-72.

INFANTE-AMATE, J. (2012b). La ordenación del espacio agrario en economías preindustriales: El caso del cultivo en el sur de España. El Futuro del Pasado, (3), 403-438.

INFANTE-AMATE, J. (2014). ¿Quién levantó los olivos?: Historia de la especialización olivarera en el Sur de España (ss. XVIII-XX). Madrid: Ministerio de Agricultura, Alimentación y Medio Ambiente.

INFANTE-AMATE, J. et al. (2014). La producción de leña en España y sus implicaciones en la transición energética: Una serie a escala provincial (1900-2000). DT-AEHE, (14).

INFANTE-AMATE, J. \& IRIARTE-GoÑI, I. (2017). Las bioenergías en España: Una serie de producción, consumo y stocks entre 1860 y 2010. DT-SEHA, (1702).

IrIARTE-GoÑI, I. (2013). Forests, Fuelwood, Pulpwood and Lumber in Spain, 1860-2000. Enviromental History, (18), 333-359.

IRIARTE-GoÑI, I. \& AYUDA, M. I. (2006). Una estimación del consumo de madera en España entre 1860 y 1935. DT- $A E H E$, (6).

JOVER, G. (2014). La difusión del trabajo asalariado infantil en la agricultura mallorquina: Una aproximación a partir de los libros de cuentas de los predios oleícolas, 1700-1850. En J. M. BorRÁs (Ed.), El trabajo infantil en España (1700-1950) (pp. 27-59). Barcelona: Icaria.

Jover, G. \& Manera, C. (2009). Producción y productividad agrícolas en la isla de Mallorca (1590-1860). Revista de Historia Económica, 27 (03), 463-498.

Jover, G. \& MoreY, A. (2003). Les possessions mallorquines: Una modalitat d'organització de l'espai agrari i l'explotació del treball. En R. Congost, G. Jover \& G. BiAGIOLI (Eds.), L'organització de l'espai rural a l'Europa mediterrània: Massos, possessions, poderi (pp. 127-238). Girona: Curbet. 
Jover, G. \& PujAdES, J. M. (2020). Mercado de trabajo, género y especialización oleícola: Mallorca a mediados del siglo XviI. Historia Agraria, (80), 37-69.

JuAN, J. (1980). La producción de aceite en Mallorca durante la Edad Moderna y su papel en la economía mallorquina. Bolletí de la Societat Arqueologica Lul-liana, (832833), 519-552.

Larrubia, R. \& Natera, J. J. (2016). La nueva estructura de los Pagos Directos en la Reforma de la PAC: 2015-2020. En A. R. Ruiz PulPón et al. (Eds.), Treinta años de la Política Agraria Común en España: Agricultura y multifuncionalidad en el contexto de la nueva ruralidad (pp. 38-54). Ciudad Real: Asociación de Geógrafos Españoles.

López ORTIZ, I. \& MELgAREJo, J. (2016). Evolución histórica de la agricultura de la provincia de Alicante, 1900-2000. En J. OlciNA \& A. M. Rico (Coords.), Libro jubilar en homenaje al profesor Antonio Gil Olcina (pp. 1.063-1.083). Ed. ampliada. San Vicente del Raspeig: Universidad de Alicante.

MALUQueR, J. (2013). La inflación en España: Un índice de precios al consumo, 18302012. Estudios de historia económica, (64). https://www.bde.es/f/webbde/SES/ Secciones/Publicaciones/PublicacionesSeriadas/EstudiosHistoriaEconomica/Fic/ roja64.pdf

MANerA, C. (2001). Història del creixement econòmic a Mallorca (1700-2000). Palma: Lleonard Muntaner.

Manera, C. (2014). Memorias de la Real Sociedad Económica Mallorquina de Amigos del País. Palma: Govern de les Illes Balears.

MANERA, C. et al. (2019). Economía y resiliencia: Análisis tipológico de las provincias españolas desde una perspectiva histórica, 1965-2011. Sistema. Revista de Ciencias Sociales, (255), 3-22.

MANERA, C. \& NAVINÉs, F. (2018). La indústria invisible, 1950-2016: El desenvolupament del turisme a l'econonomia de Balears. Palma: Lleonard Muntaner.

MARULl, J. et al. (2015). Long-Term Bio-Cultural Heritage: Exploring the Intermediate Distrubance Hypothesis in Agro-Ecological Landscapes (Mallorca, c. 1850-2012). Biodiversity and Conservation, 24 (13), 3217-3251.

MARULL, J. et al. (2016). Towards an Energy-Landscape Integrated Analysis?: Exploring the Links between Socio-Metabolic Disturbance and Landscape Ecology Performance (Mallorca, Spain, 1956-2011). Landscape Ecology, 31 (2), 317-336.

MARULl, J. et al. (2018). Exploring the Links between Social Metabolism and Biodiversity Distribution across Landscape Gradients: A Regional-Scale Contribution to the Land-Sharing versus Land-Sparing Debate. Science of The Total Environment, (619620), 1272-1285.

Memoria Comercial (MCOCIN) (1919-1945). Palma: Cámara Provincial de Comercio, Industria y Navegación de Palma. 
MESTRE, A. (1942). Exportación y comercio de productos agrícolas y pecuarios. Ejemplar mecanografiado procedente del Servicio Agronómico Provincial.

Ministerio de Agricultura, Pesca y Alimentación (MAPA) (1990-2019). Encuesta sobre Superficies y Rendimientos de Cultivos (ESYRCE). https://www.mapa. gob.es/es/estadistica/temas/estadisticas-agrarias/agricultura/esyrce/

Moll, I. (2008). Agronomia i tècniques agrícoles al segle XVIII. En I. Moll \& J. M. VIDAL (Coords.), Història de la Ciència a les Illes Balears III: La Il-lustració (pp. 267-306). Palma: Govern de les Illes Balears.

Moll, I. \& SuAU, J. (1979). Senyors i pagesos a Mallorca (1718-1860/70). Estudis d'Història Agraria, (2), 95-191.

MoreY, A. (1999). Noblesa $i$ desvinculació a Mallorca als segles XVIII $i$ XIX: Les repercussions de la legislació desvinculadora sobre els patrimonis nobiliaris. Palma/Barcelona: Universitat de les Illes Balears/Abadia de Montserrat.

Morey, A. (2013). Un exemple de comptes de pagès: Els amos de possessió: Mallorca (segles XIX-Xx). En E. SAGUER, G. Jover \& H. Benito (Eds.), Comptes de senyor, comptes de pagès: Les comptabilitats en la història rural (pp. 147-170). Girona: Documenta Universitaria.

Morey, A. (2018). Nueva Planta, estrategias hereditarias e influencias mutuas entre las instituciones vinculares de Castilla y Aragón (1715/1736-1836). En J. M. DeYÁ (Dir.), 1716: El final del sistema foral de la monarquía hispánica (pp. 335-355). Palma: Lleonard Muntaner.

Morey, A. (2019). Grupos campesinos intermedios, estilo de vida y pautas de consumo: Mallorca (1750-1836/50). Revista de Historia Moderna. Anales de la Universidad de Alicante, (37), 1-37.

MoREY, A. \& ForNÉs, J. (2019). El conreu comercial de l'ametler a les Balears: Una perspectiva històrica (segles XVIII-XX). En E. VICEDO (Ed.), X Congrés sobre sistemes agraris, organització social $i$ poder local: Cultius, especialització $i$ mercats. Lleida: Institut d'Estudis Ilerdencs.

Morey, A. \& Jover, G. (2018). From 'Feudal' to 'Common' Emphyteusis in Rural Mallorca, Eighteenth to Twentieth Centuries. En R. Congost \& P. Luna (Eds.), Agrarian Change and Imperfect Property: Emphyteusis in Europe (16 to $19^{\text {th }}$ centuries) (pp. 183-206). Turnhout: Brepols.

Morey, A., Jover, G. \& Villalonga, J. (2016). From Farm Lease to Farming to Halves: Landlors, Merchants, Lease-Holders and Sharecroppers Tenants (Mallorca, 1700-1820) En European Social Sience History Conference. Valencia, 11 marzo-3 abril.

Morey, A. \& Molina, R. (2016). El retroceso del olivar en las Baleares: Un itinerario a contracorriente de la evolución española (1800-1969). Historia Agraria, (68), 71-101. 
Morro, M. (2017). L'agricultura mallorquina del segle XX (1891-1960). Palma: Lleonard Muntaner.

MURRAY, I. et al. (2019). Biocultural Heritages in Mallorca: Explaining the Resilence of Peasant Landscape within a Mediterranean Tourist Hotspot, 1870-2016. Sustainability, 11 (7). https://doi.org/10.3390/su11071926

MuRUA, J. R. (1993). Análisis de la producción y demanda de almendra española. Documento de trabajo, (93/4). https://citarea.cita-aragon.es/citarea/bitstream/10532/202/ 1/10532-80_174.pdf

Olarieta, J. R. et al. (2011). Formiguers, a Historical System of Soil Fertilisation (and Biochar Production?). Ecosystems and Environment, (140), 27-33.

Organización de las Naciones Unidas para la Alimentación y la Agricultura (FAO) (1961-2019). Estadísticas de producción y comercio, FAOSTAT-Agriculture. http://www.fao.org/faostat/es/\#data/QC

Pablo, J. de, García Azcárate, T. \& Giacinti, M. A. (2016). Comercio internacional de almendras. Revista de fruticultura, (49), 190-209.

PAstor, B. (2016). La vinya $i$ el vi a la Mallorca de finals del segle XIX: Una revisió del tòpic de la fil-loxera. Palma: Lleonard Muntaner.

Pons, A. \& Simonet, B. (1970). Planificación del cultivo del almendro. Palma: Dirección General de Agricultura, Jefatura Agronómica de Baleares.

QuintanA, P. (1979). Producción y evolución del almendro en Mallorca. Tesina.Valencia: Universitat de València.

QuintanA, P. (1981). Algunos aspectos de la producción de la almendra en Mallorca. Palma: Gràfiques Miramar.

Rallo, J. (1986). Frutales y abejas. Madrid: Ministerio de Agricultura, Pesca y Alimentación.

Riera, F. J. \& LAMIC, J. F. (1970). Cultivo del almendro. Actualización del material recopilado por Juan Salom Calafell. 3. ${ }^{\mathrm{a}}$ ed. Barcelona: Aedos.

Romero, A., Martínez Hernández, C. \& Belmonte, F. (2012). Cambios de uso del suelo en la región de Murcia. Papeles de Geografía, (43), 19-30.

Rosselló, V. M. (1964). Mallorca: El sur y el sureste. Palma: Cámara Oficial de Comercio, Industria y Navegación.

Rosselló, V. M. (1982). Canvis de propietat i parcel-lacions al camp mallorquí entre els segles XIX i XX. Randa, (12), 19-60.

RuBí, V. (1980). El almendro. Zaragoza: Delegación Ministerio Agricultura Baleares.

Ruiz Pulpón, A. R. et al. (2016). Treinta años de la Política Agraria Común en España: Agricultura y multifuncionalidad en el contexto de la nueva ruralidad (pp. 97-110). Ciudad Real: Asociación de Geógrafos Españoles.

SAlOM, J. (1923). L'ametler. Barcelona: Escola Superior d'Agricultura. 
SATORRAs, F. (1878). Informe sobre el estado de la agricultura en la provincia de las Baleares. Palma: Imprenta de Pedro José Gelabert.

SATORRAS, F. (1883). Memoria sobre el estado de la agricultura en esta provincia. Ejemplar manuscrito procedente del Servicio Agronómico Provincial.

Socias, R. \& Couceiro, J. F. (2014). Frutos secos. En J. J. Hueso \& P. Cuevas (Coords.), Almendro y pistachero: La fruticultura del siglo XXI (pp. 183-206). Almería: Cajamar.

Socias, R. \& RALlo, J. (1996). Ensayo de polinización de los principales cultivares de almendro de Mallorca. Investigación agraria. Producción y protección vegetales, 11 (1), 21-31.

Soto, D. (2015). Del manejo multifuncional del territorio a la desarticulación productiva: Cambios en los flujos de biomasa durante el proceso de industrialización de la agricultura gallega. DT-AEHE, (1505).

SuAU, J. (1991). El món rural mallorquí: Segles XVIII-XIX. Barcelona: Curial.

Tello, E. (1983). La producció cerealícola a les petites explotacions pageses des Pla de Mallorca (1850-51). Estudis d'Història Agrària, (4), 167-194.

Tello, E. et al. (2018). From Feudal Colonization to Agrarian Capitalism in Mallorca: Peasant Endurance under the Rise and Fall of Large Estates (1229-1900). Fournal of Agrarian Change, 18 (3), 483-516.

VADELL, J. et al. (2010). Evaluación agronómica de los hormigueros. En IX Congreso de la Sociedad Española de Agricultura Ecológica. Valencia: Sociedad Española de Agricultura Ecológica.

VELASCO, J. F. (2016). La valoración de servicios ecosistémicos del cultivo del almendro en el altiplano de Andalucía Oriental. Revista Atlántica, (7), 143-152.

VELASCO, J. F. \& AzNAR, A. (2016). El mercado mundial de la almendra. Boletín Económico de ICE, (3079), 77-87. 